Portland State University

PDXScholar

1984

\title{
Measurement of low vapor pressures : a kinetic approach
}

Samuel Bernard Bliden

Portland State University

Follow this and additional works at: https://pdxscholar.library.pdx.edu/open_access_etds

Part of the Physical Chemistry Commons

Let us know how access to this document benefits you.

Recommended Citation

Bliden, Samuel Bernard, "Measurement of low vapor pressures : a kinetic approach" (1984). Dissertations and Theses. Paper 3275.

https://doi.org/10.15760/etd.3266

This Thesis is brought to you for free and open access. It has been accepted for inclusion in Dissertations and Theses by an authorized administrator of PDXScholar. Please contact us if we can make this document more accessible: pdxscholar@pdx.edu. 
AN ABSTRACT OF THE THESIS OF Samuel Bernard Bliden for the Master of Science in Chemistry presented May 30, 1984.

Title: Measurement of Low Vapor Pressures: A Kinetic Approach. APPROVED BY MEMBERS OF THE THESIS COMMITTEE:

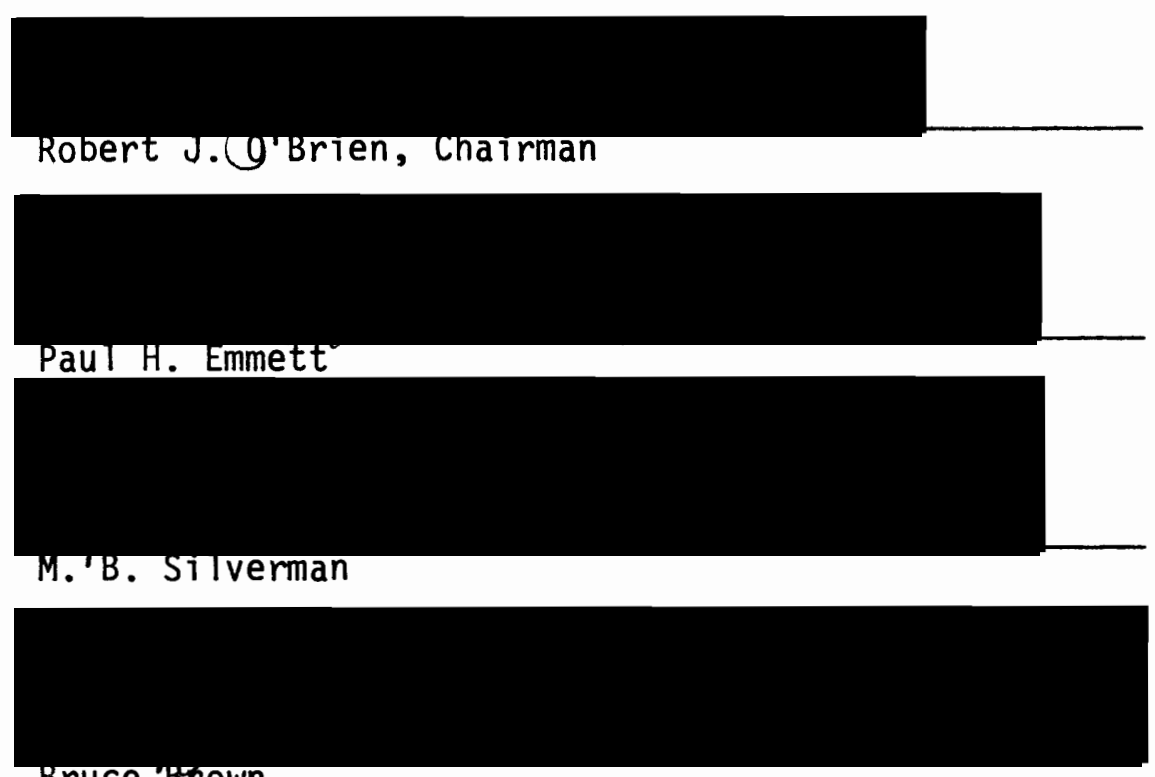

Bruce Brown

A kinetic model was applied to vapor pressure data obtained by a variable flow method. The vapor pressures of benzoic acid, naphthalene, benzophenone, and phenylhydrazine were measured at temperatures of $293 \mathrm{~K}$ to $307 \mathrm{~K}$. The data are summarized in the data table on the following page. These data were obtained by passing air over a sample of the substance in a tube. The air stream was combusted, and a flame ionization detector was used to measure the mass of $\mathrm{CO}_{2}$ so obtained. Several different flow rates were used at each temperature with each substance. 
DATA TABLE

\begin{tabular}{|c|c|c|c|}
\hline Substance & $\begin{array}{c}\text { Temperature } \\
\text { Range } \\
(\mathrm{K})\end{array}$ & $\begin{array}{c}\text { Vapor Pressure } \\
\text { Range } \\
\text { (torr) } \\
\end{array}$ & $\begin{array}{l}\text { Heat of } \\
\text { Sublimation } \\
\text { (kcal/mol) }\end{array}$ \\
\hline Benzoic Acid & $294.2-306.4$ & $.00025-.0019$ & 25.5 \\
\hline Napthalene & $297.8-307.0$ & $.085-.17$ & 14.3 \\
\hline Benzophenone & $298.0-303.8$ & $.00061-.0016$ & no calculation \\
\hline Phenylhydrazine & $293.05-294.3$ & $.0142-.0166$ & no calculation \\
\hline
\end{tabular}

A calibration factor was determined for peak heights generated by the signal from the detector on a strip chart recorder, by the use of a standard sample of $\mathrm{CO}$. Thereby, the pressure readings at flow rates varying from 0 to $60 \mathrm{cc} / \mathrm{min}$. for a given substance at a particular temperature were plotted as 1/vapor pressure vs. flow rate. The extrapolated pressure at zero flow was treated by equation (1) to yield the saturated vapor pressure of the substance at the trial temperature. (1) vapor pressure $=1 /(y$-intercept $) / \#$ carbon atoms in the substance. This relationship was derived from a kinetic treatment of an exponential dilution model. 
MEASUREMENT OF LOW VAPOR PRESSURES:

A KINETIC APPROACH

by

SAMUEL BERNARD BLIDEN

A thesis submitted in partial fulfillment of the requirements for the degree of

\section{MASTER OF SCIENCE \\ in \\ CHEMISTRY}

Portland State University

1984 
TO THE OFFICE OF GRADUATE STUDIES AND RESEARCH:

The members of the Committee approve the thesis of Samuel Bernard B1iden presented May 30, 1984.

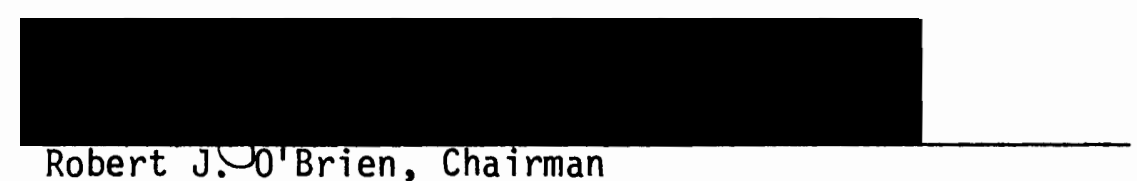

Robert J.O'Brien, Chairman

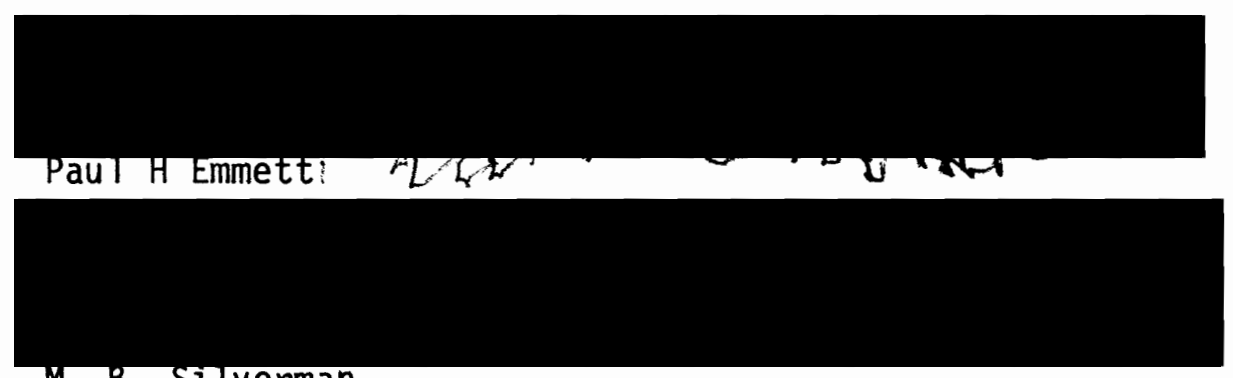

M. B. Silverman

Bruce Brown

APPROVED :

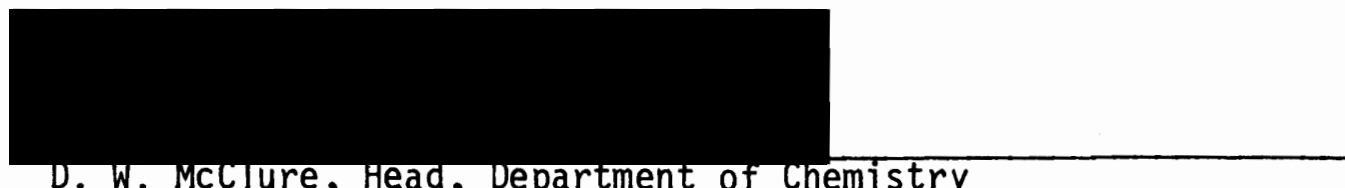

U. W. Mcciure, Head, Uepartment of Chemistry

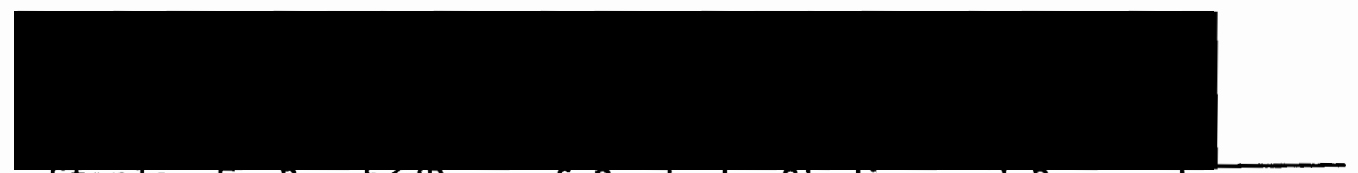

stantey E. Rauchy, Jean of Graduate Studies and Research 


\section{ACKNOWLEDGEMENTS}

This research would not have been possible without the generous support of several individuals. Bruce Dumdei set up the flow rate and oven optimization experiments, Patrick Green and Dr. M. B. Silverman repaired major sections of the glassware used in the apparatus. Rudolph Zupan and Garo Arakelian, of the Portland State University Physics Department Scientific Instrument Shop, made several needed modifications to the apparatus. F. Thomas Aldrich, Betty J. Cook, and Dennis D. Clark, from the Portland State University Chemistry Department Storeroom, provided invaluable assistance in obtaining chemicals and materials for this study. Drs. Brown, Emmett, and Silverman provided the wisdom, as members of my research advisory committee, for the completion of this research and thesis. Dr. Robert J. O'Brien, my research advisor, offered more than wisdom. Through his patience only was this work completed. Tracie Phyllis Cleaver, my friend and fiancée, ultimately was the one who received the burden of my frustrations.

To all of those named above, and to the countless others who have helped physically, mentally, and spiritually, thanks. 
TABLE OF CONTENTS

PAGE

ACKNOWLEDGEMENTS ..................... . .

LIST OF TABLES ......................... vi

LIST OF FIGURES .................................. vii

CHAPTER

I INTRODUCTION ................................... 1

Previous Methods ............... 4

Static Methods

Dynamic Methods

Summary of Previous Methods ........... . 8

Static Methods

Dynamic Methods

Current Method ............... 10

II THEORY .......................... 11

Plug Flow Model .................... 11

Exponential Dilution Model ............. 13

II EXPERIMENTAL . . . . . . . . . . . . . 15

Apparatus .................... 15

Reagents ................ 18

Procedure ................... 18

Vapor Pressure Measurements

$\mathrm{CO}_{2}$ Peak Calibration

Background Characterization

Oven Temperature Optimization

Flow Rate Optimization for Combustion 
CHAPTER

PAGE

IV RESULTS AND DISCUSSION ...................... 22

Detector Response Calibration $\left(\mathrm{CO}_{2}\right.$ Peak $)$.... 22

Experimental Test of Equation (2-22): Exponential Dilution.................. 24

Vapor Pressure Measurements . . . . . . . 24

Benzoic Acid

Naphthalene

Benzophenone

Phenylhydrazine

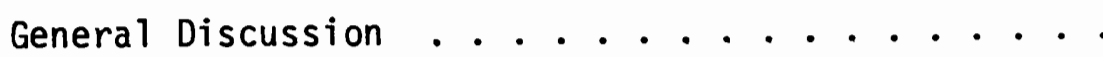

Systematic Error

Problems

Applicability of the Method

V CONCLUSIONS ........................ 60

REFERENCES ............................ 61 


\section{LIST OF TABLES}

TABLE

PAGE

I COMPARISON OF METHODS ............... 10

II RESULTS OF $\mathrm{CO}_{2}$ PEAK CALIBRATION . . . . . . . . . 22

II I BENZOIC ACID VAPOR PRESSURES . . . . . . . . . . 40

IV NAPHTHALENE VAPOR PRESSURES ............. . . 47

V BENZOPHENONE VAPOR PRESSURES ............. 50

VI PHENYLHYDRAZINE VAPOR PRESSURES ........... 53 


\section{LIST OF FIGURES}

FIGURE

PAGE

1. Diagram of Apparatus 16

2. Benzoic Acid-Plot of 1/Vapor Pressure vs. Flow a $294.2 \mathrm{~K} 27$

3. Benzoic Acid-Plot of 1/Vapor Pressure vs. Flow e 296.0K 28

4. Benzoic Acid-Plot of 1/Vapor Pressure vs. Flow $0296.05 \mathrm{~K} 29$

5. Benzoic Acid-Plot of 1/Vapor Pressure vs. Flow e 296.95K 30

6. Benzoic Acid-Plot of 1/Vapor Pressure vs. Flow e 299.9K 31

7. Benzoic Acid-Plot of 1/Vapor Pressure vs. Flow a $300.1 \mathrm{~K} 32$

8. Benzoic Acid-Plot of 1/Vapor Pressure vs. Flow @ $300.5 \mathrm{~K} 33$

9. Benzoic Acid-Plot of 1/Vapor Pressure vs. Flow a $301.15 \mathrm{~K} 34$

10. Benzoic Acid-Plot of 1/Vapor Pressure vs. Flow $0302.35 \mathrm{~K} 35$

11. Benzoic Acid-Plot of 1/Vapor Pressure vs. Flow @ 305.2K 36

12. Benzoic Acid-Plot of 1/Vapor Pressure vs. Flow a $306.4 \mathrm{~K} 37$

13. Benzoic Acid-Plot of Ln (Vapor Pressure) vs. $1 / T$

14. Naphthalene-Plot of 1/Vapor Pressure vs. Flow e $297.8 \mathrm{~K} 42$

15. Naphthalene-Plot of 1/Vapor Pressure vs. Flow @ $298.65 \mathrm{~K} \quad 43$

16. Naphthalene-Plot of 1/Vapor Pressure vs. Flow a $301.45 \mathrm{~K} 44$

17. Naphthalene-Plot of 1/Vapor Pressure vs. Flow $302.0 \mathrm{~K} \quad 45$

18. Naphthalene-Plot of 1/Vapor Pressure vs. Flow e 307.0K 46

19. Naphthalene-Plot of Ln (Vapor Pressure) vs. 1/T 49

20. Benzophenone-P1ot of 1/Vapor Pressure vs. Flow $0298.0 \mathrm{~K} 51$

21. Benzophenone-Plot of 1/Vapor Pressure vs. Flow $0303.8 \mathrm{~K}$ 
22. Benzophenone-Plot of Ln (Vapor Pressure) vs. $1 / T$

23. Phenylhydrazine-Plot of $1 /$ Vapor Pressure vs. Flow o $294.3 \mathrm{~K} 55$

24. Phenylhydrazine-Plot of 1/Vapor Pressure vs. Flow e 293.05K 56 
CHAPTER I

\section{INTRODUCTION}

There are many reasons for the development of a method allowing the rapid and efficient determination of vapor pressures in the range below 1 torr $(1 \mathrm{~mm} \mathrm{Hg})$. They can be categorized as industrial, environmental, and pure research.

Under the heading of industrial applications, the petroleum industry has measured the vapor pressures of the products of the cracking of crude oil (1). Related industries such as ink (2), grease (3), and plasticizer (4) also require low vapor pressure measurements. The importance of the first measurements lies in the determination of the effectiveness of the cracking process in breaking down large molecular weight compounds into smaller, higher vapor pressure components. Petroleum-related industries can determine the loss of products and the effectiveness of their processes by measurement of the vapor pressure of the products. Such measurements also are needed in order to evaluate safety features incorporated to prevent exposure of workers to toxic levels of known poisons and to monitor effluents entering the environment surrounding industrial plants.

In the gasification of coal as an inexpensive energy source, high molecular weight, low volatility compounds condense out of the flue gases. This can cause plugging of the effluent pipes with subsequent problems in the efficient extraction of heat energy. Vapor pressures 
in the range $10^{-1}$ to $10^{-3}$ torr have been measured to predict the amount of condensate from these compounds (5).

Organic compounds in our environment from various sources pose health problems. Chemical wastes discharged by industry into aquatic environments have included toxins such as dioxin, which has been found in parts per billion ( $10^{-6}$ torr) levels to be lethal in laboratory rats (6). Such small quantities of extremely low vapor pressure organics were found in sediments of residences in the Love Canal (7).

These chemicals partition between the aqueous, vapor, and sedimentary phases. A measure of the ratio of the amount of substance in the vapor phase to that in the aqueous phase is the Henry's law constant, which is equal to the vapor pressure of a substance above a solution of the substance in a solvent, divided by the solubility of the substance in the solvent (or the concentration of the solute in the solvent).

The Henry's law constant has been evaluated for numerous substances that are known pollutants $(8,9)$. Using this information, the transfer between the phases by a pesticide, for example, can be determined. The adsorption of pesticides onto soils and desorption into water have been determined by this relationship (9). However, the vapor pressures at ambient temperatures for many environmentally important substances have been determined by methods which are not very sensitive at low vapor pressures, and/or differ greatly from one investigator to another in their results (8).

Pesticides, when applied to plants, present two critical problems: how much remains after a period of time, and where does the substance go? Vapor pressure measurements of these low volatility compounds, in 
the millitorr and microtorr range, help to predict the evaporation rates and, therefore, the amount of residual substance (10).

Vapor from herbicides can kill both weeds and, unfortunately, nearby crops by diffusion (11). This is the case with the esters of 2,4-D (2,4-dichlorophenoxy alkyl carboxylic acids), in concentrations as low as $10^{-5}$ torr (11).

Total organic carbon, or the carbon content of the atmosphere from al1 organic compounds, is an important parameter used to determine air pollution $(12,13)$. Generally, the concentration of organic compounds in the atmosphere falls in the parts per million (ppm) or millitorr range at most. Therefore, sensitive and quick methods are desirable for detection of acute problem areas.

The third area needing low vapor pressure measurements is pure research. Studies of adsorption onto solids are facilitated by knowledge of low vapor pressures. Purnel1 (14) suggested the use of gas chromatography to determine isotherms of a sample on an adsorbing column by varying the ratio of partial pressures of sample to carrier gas. The vapor pressure must be known or approximated. Another research group (15) used gas chromatography to predict vapor pressures of homologous series of hydrocarbons and other organic compounds from theoretical bases. Exact measurements are needed to corroborate predictions made.

Gil'denblat (16) referred to the use of the vapor pressure of naphthalene in studying adsorption, absorption, and heterogeneous catalysis. Vapor pressure measurements can be used to find the mass of naphthalene transferred from the sample to a stream of gas passed over it. Thereby, adsorption of a sample on a catalyst may be observed. 
Finally, low vapor pressures of organic substances need further measurement in order to corroborate previous determinations. Several investigations $(8-10,16-20)$ have reported the disagreement among literature values. For example, naphthalene $020^{\circ} \mathrm{C}$ has been stated to have a vapor pressure of 0.124 torr (21), 0.0640 torr (22), and 0.0519 torr (23), and $025^{\circ} \mathrm{C}$ to have values of 0.2129 torr (24), 0.08512 torr (23), and 0.0820 torr (17). There is a need for a standard with which instruments and procedures might be calibrated for the future measurement of low vapor pressures. It has been suggested that naphthalene is a suitable compound due to its stability and availability in pure form $(17,23)$. Therefore, there is a need for agreement as to its vapor pressure.

\section{PREVIOUS METHODS}

Although many methods have been used for the measurement of low vapor pressures, very few are applicable to organic compounds below 1 torr. This limitation has been stated by several workers in the field of vapor pressure measurement $(4,8,11,30)$, and can be seen in the detection range stated in standard methods by the ASTM (25-27). Methods that have successfully been used can be categorized as either static or dynamic (11). The static methods measure the sample vapor at equilibrium, whereas the dynamic methods measure a vapor which has been carried off from the sample to be measured.

\section{Static Methods}

A pressure gauge placed directly in the sample compartment is 
one example of the static type. A Rodebush gauge incorporates an armature, quartz plate, and solenoid suspended together in such a way as to allow the vapor pressure of a sample to force the plate to move upward in a sample cell. A current applied through the solenoid pushes back on the plate just enough to counterbalance the vapor pressure by way of the armature. The current needed to balance a known vapor pressure calibrated the gauge. A Rodenbush gauge was used to measure the vapor pressure of benzotrifluoride (28), naphthalene, anthracene, hexachlorobenzene (22), and trimethyl benzenes (29).

A Mcleod Gauge, in which the sample vapor pressures are balanced by mercury or some other high boiling liquids, has been used for measuring the vapor pressure of maleic anhydride (20) and phthalic anhydride (30). The principle employed is the compression of vapor from one volume to a smaller one by the rising of mercury in a capitlary tube also containing the vapor. An inert gas, such as nitrogen, was used in these experiments to balance the vapor pressure of the sample, which never came into contact with the gauge. A dry ice bath was inserted between the sample and the gauge to prevent contamination by maleic anhydride, and the system was filled with nitrogen at slightly greater pressure than that anticipated for the sample. By this method, the nitrogen vapor pressure was measured. Successive readings were taken using lower nitrogen pressures until the difference between consecutive trials was zero.

An MKS diaphragm gauge, a vacuum gauge, has been used to determine the vapor pressure of naphthalene (23) and benzophenone (31). In both of these experiments, the diaphragm gauge was calibrated using a 
mercury manometer or dead weight gauge.

An indirect method of measuring low vapor pressures that has been used extensively $(1,11,30)$ is the measurement of the boiling point of a sample at a known applied pressure and the extrapolation by way of equations such as the Antoine and Clausius Clapeyron to the vapor pressure at lower temperatures.

Dynamic Methods

Effusion methods based on the work of M. Knudsen (32) either measure the weight of a sample after some vapor has effused through a small hole in the sample vessel, or the actual mass effused. The effusion cell typically is a box with a small hole at the top and sample inside. This is enclosed by a large tube that is connected to a cold trap and a vacuum pump. Naphthalene, p-chloroaniline, p-chloronitrobenzene, and $\mathrm{p}$-bromonitrobenzene vapor pressures were determined in this way, as were benzoic acid and benzophenone $(19,33)$. Similarly, several aromatic compounds, including naphthalene and anthracene, vere measured (18).

A modification of the previous effusion methods that eliminated the necessity for weighing the sample cell periodically, incorporated a condensing surface for the effusing vapors (11). The condensed vapor was extracted from the surface and its absorbance measured by ultraviolet spectrometry. Pesticides with vapor pressures from $10^{-3}$ down to $10^{-7}$ torr were studied.

The jet or torsion effusion method is a variation of the previous methods that does not measure the mass loss of the sample, but does measure the torque produced as a result of the twisting of a wire due to 
the effusing of sample from a sample cell suspended by the wire. A galvanometer suspended above the sample cell was used to measure the torque applied by effusing acridine (34).

The gas saturation method has been used in numerous modifications to measure the low vapor pressure of organic compounds. In all of these methods a stream of air, nitrogen, or other inert gas is saturated with the sample. The vapor pressure of the sample is assessed in various ways.

In a method used to measure the vapor pressures of triazines in the $10^{-5}$ to $10^{-6}$ torr range (35), a column was packed with sample. Nitrogen was passed through to a chromatographic column, surrounded by solid $\mathrm{CO}_{2}$ to condense the sample vapor taken up by the carrier gas. The chromatographic column was taken out of the system and the sample eluted by warming the column. A gasometer at the end of the system was used to measure the volume of carrier gas passed through the sample column.

Several hydrocarbons and other organic compounds were studied in the range $10^{-1}$ to $10^{-4}$ torr using a similar method (3), but eliminating the chromatographic column. The latter two saturation methods used flame ionization detectors to measure eluted sample.

In another variation, air was drawn by aspiration through a stainless steel tube packed with naphthalene (16). The saturated airstream was not measured. However, the sample tube was weighed to determine naphthalene vapor pressure by difference,

Anthracene and triethylene glycol di-2-ethylbutyrate vapor pressures were determined using several saturation tubes packed with sample in series followed by a chromatographic column (4). The carrier 
gas was timed in its flow and the flow rate was measured to evaluate the quantity of sample eluted from the column. A flame ionization detector was used to produce values in the microtorr to torr range.

An important addition to the gas saturation method was the combustion of the organic compound before detection. By this method, naphthalene (17) and several other solids and liquids (5) with vapor pressures in the $10^{-1}$ to $10^{-3}$ torr range were measured using an infrared detector in both cases. In this method the quantity detected was total carbon from the sample. All carbon atoms in a substance were converted to $\mathrm{CO}_{2}$. Therefore, an organic compound with 10 carbon atoms would be converted to ten times as many moles of $\mathrm{CO}_{2}$ as there were of the compound itself. Division of the number of moles of $\mathrm{CO}_{2}$ found by the number of carbon atoms in the substance would give the number of moles of substance measured.

\section{SUMMARY OF PREVIOUS METHODS}

Static Methods

Rodebush Gauge. Errors are due to movement of the quartz plate, response rate of the solenoid producing the balancing current, deviation from the ideal gas law, adsorption onto capillary tubing by the sample and by mercury. The absolute error was $4.8 \%(28,29)$ in the experiments mentioned. The method was applicable in the micron $\left(10^{-3}\right.$ torr $)$ range. McLeod Gauge. Corrosive organics can damage the gauge; therefore, the sample must be sealed off from the gauge. Temperature control, diffusion of sample vapors away from the gauge, and stopcock grease outgassing can cause errors (20). In the measurement of maleic anhydride 
(20) the error was considered to be at least 0.05 torr in the largest measurements, or approximately $5 \%$. This method was appropriate in the micron range.

Diaphragm Gauge. Thermal transpiration and sample condensation on the gauge are problems. The error in the naphthalene experiment was $2-5 \%$ over the range of temperatures (23). Naphthalene vapor pressures were measured down to the millitorr range.

Boiling Point Methods. Solid samples are difficult to measure. Since the values at low vapor pressures are extrapolated from higher values by curve fitting $(1,8,11,30)$, the error is difficult to trace. Generally, the range is down to 1 torr $(8,11)$.

Dynamic Methods

Effusion. Long time periods are needed for accumulating measurable amounts of sample effused or lost for very low vapor pressure samples. Condensation of the sample on the large tube walls interferes with the measurements, as does incorrect geometry with regards to hole diameter and depth (18, 33). Temperature control is a main problem (19). Swan and Mack (33) estimated an error of 1-2\%; Hamaker et al (11) predict an accuracy of "better than 10-20\%" for many of their results. The lowest range measured in these experiments is the microtorr range.

Torsion Effusion. Temperature changes in the sample occur with time (31). The zero point can change during an experiment due to the wear inherent in the pendulum-like apparatus (31). Temperature control is also a problem in this method. No error estimation was given in the study of the vapor pressure of acridine; however, the detection limit was stated to be 3 microtorr (34). 
Gas Saturation Methods. Most variations require many hours for one experiment. If saturation conditions are not met, the results are invalid. The infrared detector used in two modifications $(5,17)$ is not as sensitive as the flame ionization detector used in other gas saturation methods. For example, the instrument used in the determination of the vapor pressures of naphthalene (17) was readable on a scale of 0-100 ppm (0-76 millitorr) to $\pm 1 \mathrm{ppm}$ (17). Flame ionization allows for measurements below $10^{-2} \mathrm{ppm}$.

\section{TABLE I}

COMPARISON OF METHODS

\begin{tabular}{lrcc}
\multicolumn{1}{c}{ Method } & $\begin{array}{c}\text { Detection Limit } \\
\text { or Range Used }\end{array}$ & Error \\
\cline { 3 - 3 } Rodebush Gauge & $10^{-3}$ torr & $4.8 \%$ \\
McLeod Gauge & $10^{-3}$ torr & $5 \%$ \\
Diaphragm Gauge & $10^{-3}$ torr & $2-5 \%$ \\
Boiling Point & 1 torr & $10^{-6}$ torr & -- \\
Effusion & $3 \times 10^{-6}$ torr & $1-2 \%$ and $10-20 \%$ \\
Torsion Effusion & $7.6 \times 10^{-6}$ torr &.- \\
Gas Saturation & $10^{-6}$ torr & $-\cdots$ \\
Current Method &
\end{tabular}

CURRENT METHOD

This research developed a kinetic approach to the dynamic measurement of vapor pressures, allowing extrapolation of measured flows to zero flow rate. This approach is essential with small quantities of sample where saturation may be difficult to obtain. 


\section{CHAPTER II}

\section{THEORY}

Two different situations are considered here in evaluating the vapor pressure of a sample by a dynamic gas saturation method. A1though these variants have previously been discussed by Porter (36) and Pecsok (37) in reference to the extremes of sample charging in gas chromatography, no kinetic analysis has been presented. The two models are explained below.

\section{PLUG FLOW MODEL}

The carrier gas may be "charged" with the sample as it proceeds through the cell. If the carrier acts like a "plug" of a fixed and extremely small length, the amount of a sample vapor which it picks up as it passes through the cell will depend upon the time it remains in the cell. This is dependent on the flow rate being inversely proportional to it. In this case, the evaporation and condensation of the sample are the only factors considered. The plug is carried off from the cell with no dilution.

Kinetically, if $k_{e}$ represents the evaporation rate, $k_{c}$ the rate of condensation, $L$ a function of the surface area of the sample in the condensed phase, and $G$ the sample vapor concentration,

$$
L \frac{k_{e}}{k_{c}} G+L
$$


This leads to the rate of formation of sample vapor

$$
\frac{d G}{d t}=k_{e} L-k_{c} G L
$$

$$
\frac{d G}{d t}=\left(k_{e}-k_{c} G\right) L
$$

Separating the variables and integrating

$$
s_{0}^{G} \frac{d G}{k_{e}-k_{c} G}=L s_{0}^{T} d t
$$

where $T$ is the residence time of the carrier gas in the sample cell, and

$$
\frac{-1}{k_{c}} \frac{\ln \left(k_{e}-k_{c} G\right)}{k_{e}}=L T
$$

$$
\ln \left(1-k_{c} G / k_{e}\right)=-k_{c} L T
$$

The ratio of the evaporation rate to the condensation rate is the saturation vapor pressure $G_{0}$
$(2-7)$
$k_{e} / k_{c}=G_{0}$

Thus,

$$
\ln \left(1-G / G_{0}\right)=-k_{c} L T
$$

The residence time $T$ is the volume divided by the flow rate

$$
T=v / f
$$


where $f$ is the flow rate in $c c / m i n$ and $v$ is the sample cell volume in cc. Substituting a constant, $C$, for $-k_{c} L v$ and substituting (2-9) into $(2-8)$,

$$
\ln \left(1-G / G_{0}\right)=C / f
$$

An initial guess is used as a first approximation for $G_{0}$, and a least squares fit is performed on the plot of $\ln \left(1-G / G_{0}\right)$ versus $1 / f$ data. A straight line should result if the correct $G_{0}$ was chosen. $G_{0}$ is then varied until the best straight line is obtained, based on correlation coefficients. The slope of the line will be the constant $C$.

Alternately, rearranging equation (2-10),

$$
1-G / G_{0}=e^{C / f}
$$

$$
G=G_{0}-G_{0} e^{C / f}
$$

A plot of $G$ versus $e^{C / f}$ will have $G_{0}$, the saturated vapor pressure of the sample, as the $y$-intercept. Here, $C$ is then varied until the best linear fit is obtained.

\section{EXPONENTIAL DILUTION MODEL}

In this model, the sample is mixing with the carrier gas continuously, and the concentration is constant only at time zero. The carrier gas enters the cell at zero concentration of sample and carries off some sample vapor. The longer the residence time of the carrier gas in the sample cell, the greater the amount of dilution. Using $G$ and $L$ as before and then adding an equation for dilution 
$(2-14)$

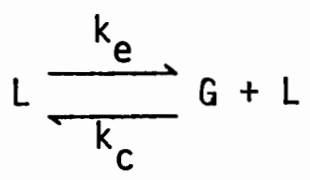

$(2-16)$

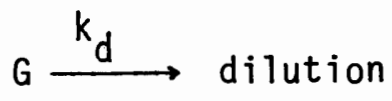

$$
\frac{d G}{d t}=k_{e} L-k_{c} G L-k_{d} G
$$

If a steady state concentration leaves the saturation chamber,

$(2-17)$

$$
\frac{d G}{d t}=0=k_{e} L-k_{c} G L-k_{d} G
$$

Solving for $G$,

$$
G=k_{e} L /\left(k_{c} L+k_{d}\right)
$$

Inverting

$$
1 / G=k_{c} / k_{e}+k_{d} / k_{e} L
$$

Substituting (2-7) into (2-19)

$$
1 / G=1 / G_{0}+k_{d} / k_{e} L
$$

The dilution rate constant is related to the flow and volume of the sample cell by

$$
k_{d}=f / v
$$

Substituting (2-21) into (2-20),

$$
1 / G=1 / G_{0}+f / k_{e} V L
$$

A plot of $1 / G$ versus $f$ has $1 / G_{0}$ as the $y$-intercept. $G_{0}$ is the sample saturated vapor pressure.

The vapor pressure readings in each case in this method will be proportional to the measured peak height on a chart recorder from a signal of a flame ionization detector which has been calibrated by a standard of known concentration. 
CHAPTER III

\section{EXPERIMENTAL}

\section{APPARATUS}

The equipment used included a Perkin-Elmer model 3920 Gas Chromatograph with a flame ionization detector of the forced air diffusion type capable of detecting $5 \times 10^{-12} \mathrm{gm} / \mathrm{sec}$. hydrocarbon, sensitive to 0.015 coulomb/gm., and having less than $3 \times 10^{-14} \mathrm{amp}$ $\left(6 \times 10^{-3}\right.$ coulomb/gm.) noise. The detector and electrometer amplifier are linear over a range of at least $10^{6}$, the electrometer experiencing noticeable noise at the lowest attenuated signal due to the flame (38). The flame ionization signal was fed to a Perkin-Elmer model 023 strip chart recorder using a $1 \mathrm{mv}$. full scale range. For $\mathrm{CO}_{2}$ measurements, a 3-foot long glass column of 1/8 in. OD packed with Poropak QS was used at room temperature. Calibration of the detector signal was accomplished with the aid of a 6 -foot long glass column packed with Carbosieve $S$ operating in parallel with the previously mentioned column.

Figure 1 shows a schematic of the apparatus. A micrometer valve controlled the saturator gas flow into a 6-port sampling valve produced by Portland Valve Company. One outlet from this latter valve contained a soapbubble flow meter for measurement of gas flow through the sample cell. A stainless steel sample loop of $2.70 \mathrm{mr}$. was attached to two other sample valve outlets. Two more outlets contained 


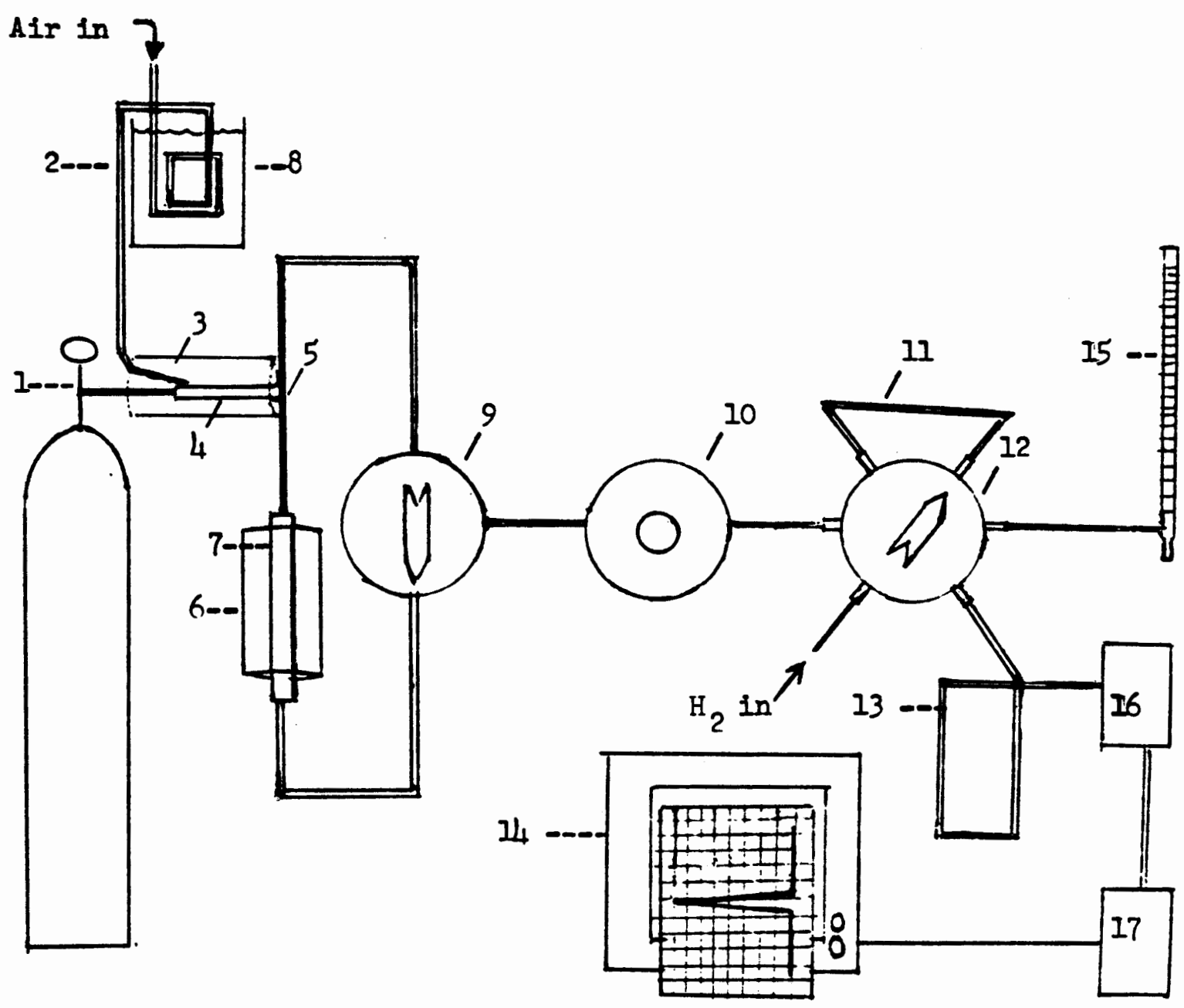

Flgure 1. Diagram of apperatus

(1) non air tank; (2) Cu tubing; (3) cardboard insulating tube; (4) sample tube, packed with sample and sealed at both ends with glass wool; (5) t-connection; (6) encased heater wire for oxidation oven; (7) quartz tube with $\mathrm{MnO}_{2}$ catalyst, sealed with glass wool at both ends; (8) temperature bath; (9) 2-way selector switch for selecting "TC" or "CO " branch of air streami (10) micrometer valve for controlling flow rate; (II) 2.70cc sample loop of stainless steel; (12) 6-port sample valve; (13) chramatographic column, one meter long packed with Foropak QS adsorbent; (14) strip chart recorder; (15) soapbubble meter for masuring flow rate; (16) methanator, with $\mathrm{NI}$ supported on firebrick, for reducing $\mathrm{CO}_{2}$ to $\mathrm{CH}_{4}$; (I7) flame ionization detector. 
a line connecting hydrogen gas for flushing the sample loop contents onto the column and the column line connection itself. The sixth outlet joined the micrometer valve to the sample valve. Combustion of hydrocarbons to $\mathrm{CO}_{2}$ was done in a thick-walled quartz tube $\frac{1}{2}$ in. OD and 9 in. long, enclosed at both ends with glass wool and containing $\mathrm{MnO}_{2}$ catalyst for oxidation as used by Johnson and Huntzicker (13). The tube was heated by heater wire to $670^{\circ} \mathrm{C}$.

The combustion tube was about $1 \mathrm{ft}$. downstream from the sample cel1. To prevent condensation of sample vapor between the sample cell and the combustion area, nichrome wire was wrapped around the connecting tubing and connected to a variable transformer to heat the line at least $50^{\circ} \mathrm{C}$ above the temperature of the sample cell.

The sample cell was surrounded by a cardboard tube, and air was passed through the tube and over the sample cell after having been warmed in a constant temperature bath to the desired temperature.

From the column, the mobile phase passed through a methanator after the design of Johnson and Huntzicker (13). Ni coated on firebrick acted as the reduction catalyst for conversion of all $\mathrm{CO}_{2}$ to methane, since the flame ionization detector cannot detect $\mathrm{CO}_{2}$.

In this system, hydrogen carrier gas doubled as the detector gas, being fed through the column with the sample, reaching the mathanator, and ending up at the base of the flame ionization jet. The hydrogen flow rate used was $34.2 \mathrm{cc} / \mathrm{min}$, , and the compressed air used for the detector had a flow rate of $300 \mathrm{cc} / \mathrm{min}$.

The sample cell was a glass tube approximately 5 in. long and $1 / 8$ in. OD, each end plugged with glass wool. Most of the remaining tubing 
was thick-walled glass capillary tubing $\frac{1}{4}$ in. 00 .

\section{REAGENTS}

Samples used were analytical grade naphthalene, benzoic acid, benzophenone, and phenylhydrazine from J. T. Baker. The calibration standard was a cylinder of $20.0 \pm 0.1 \mathrm{ppm}$. CO in air from Energetics, Inc. The catalysts used were reagent-grade $\mathrm{MnO}_{2}$ from Malinckrodt, Inc. and $\mathrm{Ni}$ on a firebrick. The saturator gas was " 0 " air from Airco rated at less than $0.1 \mathrm{ppm}$. hydrocarbon impurities as methane. Compressed air and hydrogen were also from AirCo.

\section{PROCEDURE}

\section{Vapor Pressure Measurements}

A stream of pure air was passed through a tube containing the sample (see Figure 1). A t-connection at the end of the sample cell led in one direction to a 2-way selector valve connected to a micrometer valve for metering the flow rate. The metering valve was attached to a 6-port sampling valve. The other leg of the t-connection directed the air stream through the combustor. After combustion, the gas was directed to the same sampling valve as previously described.

The 2-way valve selected which branch of the system was to be sampled by the sampling valve--either the air stream which was passed through the oxidation oven or the air stream which was not. The sample valve was arranged in a manner such that in one of two modes, it sampled the air stream selected. In this mode, the vapor entered the sample loop. In the other mode ("inject"), the sample loop was 
exposed to a hydrogen gas line which injected the contents of the sample loop onto the Poropak QS column.

By this arrangement, the sample loop sampled either the stream which contained hydrocarbon or other organic compounds used as the sample and any $\mathrm{CO}_{2}$ present as contaminant in the system, or the stream which had any contaminant $\mathrm{CO}_{2}$ present plus the $\mathrm{CO}_{2}$ from combustion of the sample. The $\mathrm{CO}_{2}$ produced from combustion of the sample was thus determined by difference of the two lines.

A typical experiment included sampling of the air stream at flow rates from $1 \mathrm{cc} / \mathrm{min}$. to $60 \mathrm{cc} / \mathrm{min}$. Injections of samples from the sample loop were made after 10 to 20 minutes of sampling in order to allow the stream to fill the loop and come to thermal equilibrium. The signal obtained from the line from the oxidation oven was called the total carbon reading (TC), and that derived from the line which bypassed the oven was the $\mathrm{CO}_{2}$ reading. The latter reading was the baseline reading. The temperature for each injection was read from a mercury-in-glass thermometer which had been calibrated at the boiling and freezing points of water, corrected for barometric pressure. The thermometer was placed near the sample tube through a hole in the surrounding cardboard tube. Temperature was varied by passing the air through copper tubing coiled in a constant temperature bath prior to passing through the cardboard tube over the sample cell.

Flow rates were varied by the micrometer valve connected between the $\mathrm{TC} / \mathrm{CO}_{2} 2$-way selector valve and sample loop (see Figure 1). Flow rates could be read in either the "sample" or "inject" modes of the sample valve by use of a soapbubble meter. Since the gas stream entered 
the column before entering the methanator, the signal measured on the chart recorder was the peak corresponding to the retention time of $\mathrm{CO}_{2}$ at approximately 6 minutes. Generally, the TC stream was sampled first at each flow rate used, and then the $\mathrm{CO}_{2}$ stream was alternated. For most trials, there were at least duplicate runs at each flow rate until reproducibility was seen to $\pm 5 \%$. Before each day's trials, the system was flushed by purging with the " 0 " air at very high flows for at least one hour (greater than $100 \mathrm{cc} / \mathrm{min}$. ).

\section{$\mathrm{CO}_{2}$ Peak Calibration}

A standard cylinder of $C O$ at $20.0 \mathrm{ppm}$. in air was used. Injections of $1,2,3 \mathrm{cc}$. were made using a $5 \mathrm{cc}$. syringe into the parallel Carbosieve S column, which had excellent separation characteristics for CO. CO was also reduced to methane before detection, just as $\mathrm{CO}_{2}$ had been. Peak areas were measured using the width at $\frac{3}{2}$ peak height times the base. The concentrations were converted to a calibration factor corresponding to the $2.70 \mathrm{ml}$. sample loop used in the vapor pressure measurements. $\mathrm{CO}_{2}$ peak areas were calibrated by this factor.

\section{Background Characterization}

Leaks in the system were detected using an empty sample ce11, and eliminated. The background due to hydrocarbons and other impurities in the " 0 " air was investigated by repreated injections of "samples" from the "TC" and $\mathrm{CO}_{2}$ lines with an empty sample cell. Equal readings of less than $0.15 \mathrm{ppm}$. were obtained, which varied from tank to tank. This was attributed to the impurities in the air tanks. This background was attained after 5 tubes of molecular sieve were added to the 
hydrogen gas line.

Oven Temperature Optimization

A sample of propene was injected into a 2401 . flask with a sidearm connection into this sampling system. The sample concentration was determined by use of a vacuum system. Tbe propene cannister was connected to the vacuum system, and a sample bulb of known volume was connected in parallel into the same system. The bulb was filled with propene and the pressure noted, as was the temperature. The sample was flushed into the large flask, which was filled with zero air to a known pressure.

A monel thermocouple was placed in the oxidation oven area and a strip chart recorder connected to this was used to determine when the signal was at a maximum. The sample flow rate was $30 \mathrm{cc} / \mathrm{min}$.

The temperature was varied by use of a variac, and it was seen that the maximum signal was reached at $670^{\circ} \mathrm{C}$.

Flow Rate Optimization For Combustion

Using propene in the same manner as above, flow rate was varied to find the limit for optimum combustion at $670^{\circ} \mathrm{C}$. Flows from $0.5 \mathrm{cc} / \mathrm{min}$. to $100 \mathrm{cc} / \mathrm{min}$. were passed through the oven. The signal generated was found to be at a maximum for flows up to $60 \mathrm{cc} / \mathrm{min}$. and then dropped off gradually at higher flows. Therefore, all experiments were carried out at flow rates of less than $60 \mathrm{cc} / \mathrm{min}$. 
CHAPTER IV

\section{RESULTS AND DISCUSSION}

DETECTOR RESPONSE CALIBRATION $\left(\mathrm{CO}_{2}\right.$ PEAK $)$

The detector response was calibrated using 15 injections each of 1,2 , and $3 \mathrm{cc}$. of a standard carbon monoxide $(20.0 \pm 0.1 \mathrm{ppm}$.) in air by syringe. The results are recorded in Tabie II.

\section{TABLE II}

RESULTS OF $\mathrm{CO}_{2}$ PEAK CALIBRATION

\begin{tabular}{|c|c|c|c|c|}
\hline $\begin{array}{l}\text { Average peak } \\
\text { height per } c c \text {. } \\
\text { of } C O\end{array}$ & $\begin{array}{l}\text { Co peak ht. } \\
\text { calibration } \\
\text { ( } 3 \text { cc. inj.) }\end{array}$ & $\begin{array}{l}\text { Co peak area } \\
\text { calibration } \\
\text { (as a } 2.70 \mathrm{ml} \\
\text { injection- } \\
\text { sample loop) }\end{array}$ & $\begin{array}{l}\mathrm{CO}_{2} \text { peak ht. } \\
\text { caîibration } \\
(2.70 \mathrm{~m} 1 \text { inj. })\end{array}$ & $\begin{array}{l}\text { C0 mass } \\
\text { detection }\end{array}$ \\
\hline$(\mathrm{cm})$. & $(\mathrm{ppmCO} / \mathrm{cm})$. & $\left(\mathrm{ppmCO} / \mathrm{cm}^{2}\right)$ & $\left(\mathrm{ppmCO}_{2} / \mathrm{cm}.\right)$ & $(\mathrm{pgCO} / \mathrm{cm})$ \\
\hline 128.00 & 0.0525 & 0.5838 & 0.0584 & 18.4 \\
\hline
\end{tabular}

Chart recorder peak areas were determined by the product of the peak height and the peak width at $\frac{1}{2}$ the peak height. The peak retention time on the $6 \mathrm{ft}$. 1ong, 1/8in. OD column packed with Carbosieve $\mathrm{S}$ was approximately 6 minutes, with no apparent peaks within three minutes on either side of the $C O$ peak. The attenuation of the signal was $\times 16$ for the 1 and $2 \mathrm{cc}$. injections and $\times 32$ for the $3 \mathrm{cc}$. injection. A chart speed of $20 \mathrm{~cm} / \mathrm{hr}$. produced peaks of $0.10 \mathrm{~cm}$. width at $\frac{1}{2}$ peak height.

The average of the peak heights for each of the 1 and $2 \mathrm{cc}$. 
injections were extrapolated to their equivalent values of $\mathrm{ppm} \mathrm{CO} / \mathrm{cm}$. of chart height at $3 \mathrm{cc}$. using equation (4-1).

$$
\frac{\mathrm{ppm}}{\mathrm{cm} .}=\frac{20 \mathrm{ppm} .}{\text { peak height }(\mathrm{cm} .)} \times \frac{\text { actual injection (cc.) }}{3 \mathrm{cc} .}
$$

These are recorded as an average of all injections in column 2 of Table II.

Since the peak widths at $\frac{1}{2}$ of the peak heights were al1 $0.10 \mathrm{~cm}$. for the $\mathrm{CO}$ peaks, the average peak heights were multiplied by $0.10 \mathrm{~cm}$. to obtain the average peak areas for each of the 1,2 , and $3 \mathrm{cc}$. injections. Then equation (4-2) was used to extrapolate each of these areas to the $\mathrm{ppm}$. $\mathrm{CO} / \mathrm{cm}^{2}$ value for a $2.70 \mathrm{cc}$. injection, the injection size of the sample loop used in the vapor pressure measurements.

$$
\frac{\mathrm{ppm} C O}{\mathrm{~cm}^{2}}=\frac{20 \mathrm{ppm} .}{\text { area }} \times \frac{\text { injection (cc.) }}{2.70 \mathrm{cc}}
$$

These extrapolations were made in order ot calibrate the $\mathrm{CO}_{2}$ peaks in the vapor pressure measurements performed on a parallel Poropak QS column. The results are displayed in column 3 of Table II. The average of the ppm. $\mathrm{CO} / \mathrm{cm}$. of chart peak height calculations was $0.5838 \mathrm{ppm} / \mathrm{cm}$. The $\mathrm{CO}_{2}$ peaks derived from sample injections onto the parallel column at the same chart speed also had peak widths at $\frac{1}{2}$ peak heights of 0.10 $\mathrm{cm}$. Therefore, the calibration factor used was $0.0584 \mathrm{ppm} \mathrm{CO}_{2} / \mathrm{cm}$. of chart peak height. The standard deviation was $0.006 \mathrm{ppm} / \mathrm{cm}$., or approximate ly $10 \%$.

The mass of $\mathrm{CO}$ measured for each injection was calculated using the ideal gas law and the molecular weight of $\mathrm{CO}$. An example of this is shown in (4-3) and (4-4) for a 1 cc. injection. 
(4-3) (1 atmosphere) $\frac{(20)}{10^{6}}\left(10^{-3} 1.\right)={ }{ }_{C O}\left(0.0821 \frac{1-\mathrm{atm}}{\mathrm{moT-K}}\right)(293 \mathrm{~K})$

(4-4) $\quad \mathrm{n}_{\mathrm{CO}}=\frac{\text { mass CO }}{28 \mathrm{~g} / \mathrm{mol}}$

The average mass calculated from 1,2 , and $3 \mathrm{cc}$. injections of $\mathrm{CO}$ was $18.4 \mathrm{pg}$ (picograms)/cm., as shown in Table II.

EXPERIMENTAL TEST OF EQUATION (2-22): EXPONENTIAL DILUTION

Porter (36) has suggested that the exponential dilution model fits his data better than the plug flow model. This model using (2-22) was applied to vapor pressure data for several temperatures for benzoic acid (Figures 8, 10-12) and naphthalene (Figures 15 and 16). The fit in each of these cases appears reasonable.

\section{VAPOR PRESSURE MEASUREMENTS}

A11 of the vapor pressure calculations are shown in ppm., torr, and pa. in Tables III-IV. The conversions are $1 \mathrm{ppm} .=7.6 \times 10^{-4}$ torr, and 1 pa. $($ pascal) $=760 / 101325$ torr. Temperatures used for data from this study are averages of the temperature ranges under which the experiments were performed. The ranges of temperatures during a given experiment varied as much as $1.3^{\circ} \mathrm{C}$. The larger variations were found at higher temperatures.

The slopes of the least squares lines vary from one plot of $1 /$ vapor pressure versus flow to the next due to changes in temperature from one experimental run to the next and errors due to variation of the temperature during individual runs. Other errors affecting these plots, and the vapor pressures derived from them, are discussed subsequently. 
The saturated vapor pressures were determined for each of the substances used by extrapolation of the plots of 1/vapor pressure versus flow rate of carrier gas through the sample cell to zero flow. The $y$ intercepts in each case determined the total carbon vapor pressure, since the organic compounds were combusted to $\mathrm{CO}_{2}$. Therefore, a compound such as benzoic acid, with 7 carbons, would produce 7 moles of $\mathrm{CO}_{2}$ for each mole of benzoic acid combusted. Equation (4-5) was used to determine a substance's vapor pressure from these plots.

(4-5) vapor pressure $=(1 /$ intercept $) / \#$ carbon atoms in compound

Tables are presented (III-VI) for each compound used in this study showing temperatures of the trials and the vapor pressures determined. Literature values of vapor pressures in the appropriate temperature range for these substances are also presented where available. Figures are also presented in the case of benzoic acid, naphthalene, and benzophenone, plotting in vapar pressure versus $1 / T$. The slope of the best fit for these figures, when multiplied by the universal gas constant, gives the heat of sublimation for the substance as per the integrated form of the Clausius-Clapeyron equation.

Benzoic Acid

Benzoic acid was chosen for study since its vapor pressure is in the 1 mtorr range at ambient temperatures. Figures 2-12 are the plots of 1/vapor pressure versus flow rate for benzoic acid samples of $0.2 \mathrm{~g}$. The temperature range was 294.2-306.4K. The plots in Figures 2, 3, 8, and 10-12 approximate linear data, with correlation coefficients greater than .90 in each case. Figure 6 appears to represent saturation 
conditions. Figures $4,5,7$, and 9 could arguably be plots of 2 nd degree equations.

Although there is not a proportionate change in the slopes of Figures 2-12 with increase in temperature, the slopes of the plots at higher temperatures are lower than those at lower temperatures by up to four orders of magnitude. It is noteworthy that the slope in Figure 2 at $294.2 \mathrm{~K}$ is more than an order of magnitude greater than any other, and the slope of the plot at $299.9 \mathrm{~K}$ (Figure 6) is more than an order of magnitude smaller than any other, although it is approximately in the center of the temperature range used. Temperature variation during the individual runs account for a measure of the inability to derive a direct relationship between slope and temperature. The fact that these trials at different temperatures were not made consecutively, but were separated in many cases by several weeks, adds deterioration of the sample surface area as a possible factor.

Table III displays the current vapor pressure data, compared to that of van Ginkel (19). Also shown are the correlation coefficients and slopes of the plots from Figures 2-12. Only the 6 vapor pressure data from the literature within the temperature range used here were compared.

From Table III comparisons can be made using the ppm. columns on either side of the temperature column. Generally, the current data are lower than van Ginkel's. Using closely-related temperatures, the values at 294.1 and $294.2 \mathrm{~K}$ show a $47 \%$ difference (.62 ppm. vs. $.33 \mathrm{ppm}$.). The $.91 \mathrm{ppm}$. from the current data agrees with the $.90 \mathrm{ppm}$. value from the literature, both being recorded at approximately $297 \mathrm{~K}$. The current 


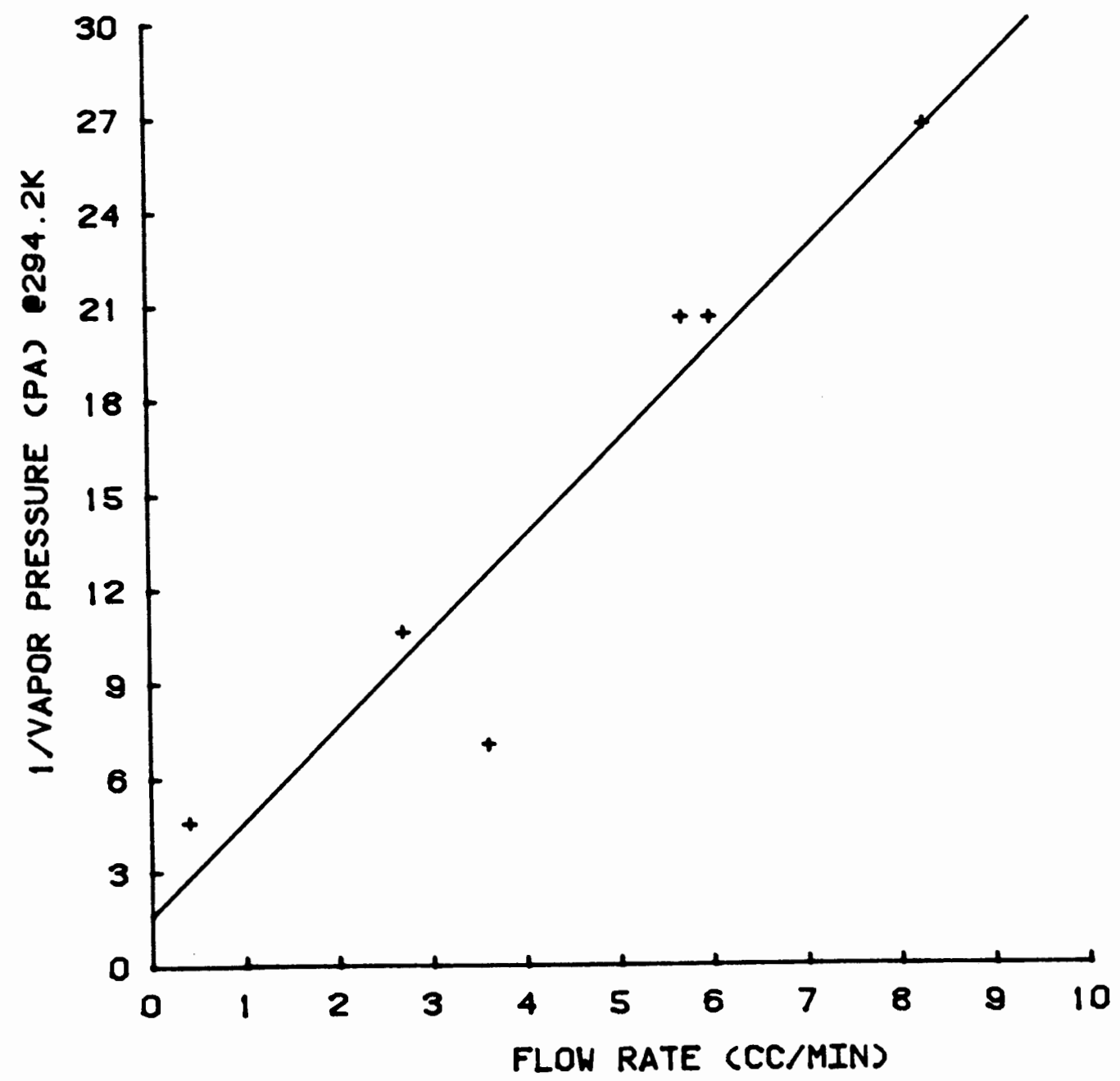

Figure 2. Benzoic acid-plot of 1/vapor pressure vs. flow @ 294.2K 
28

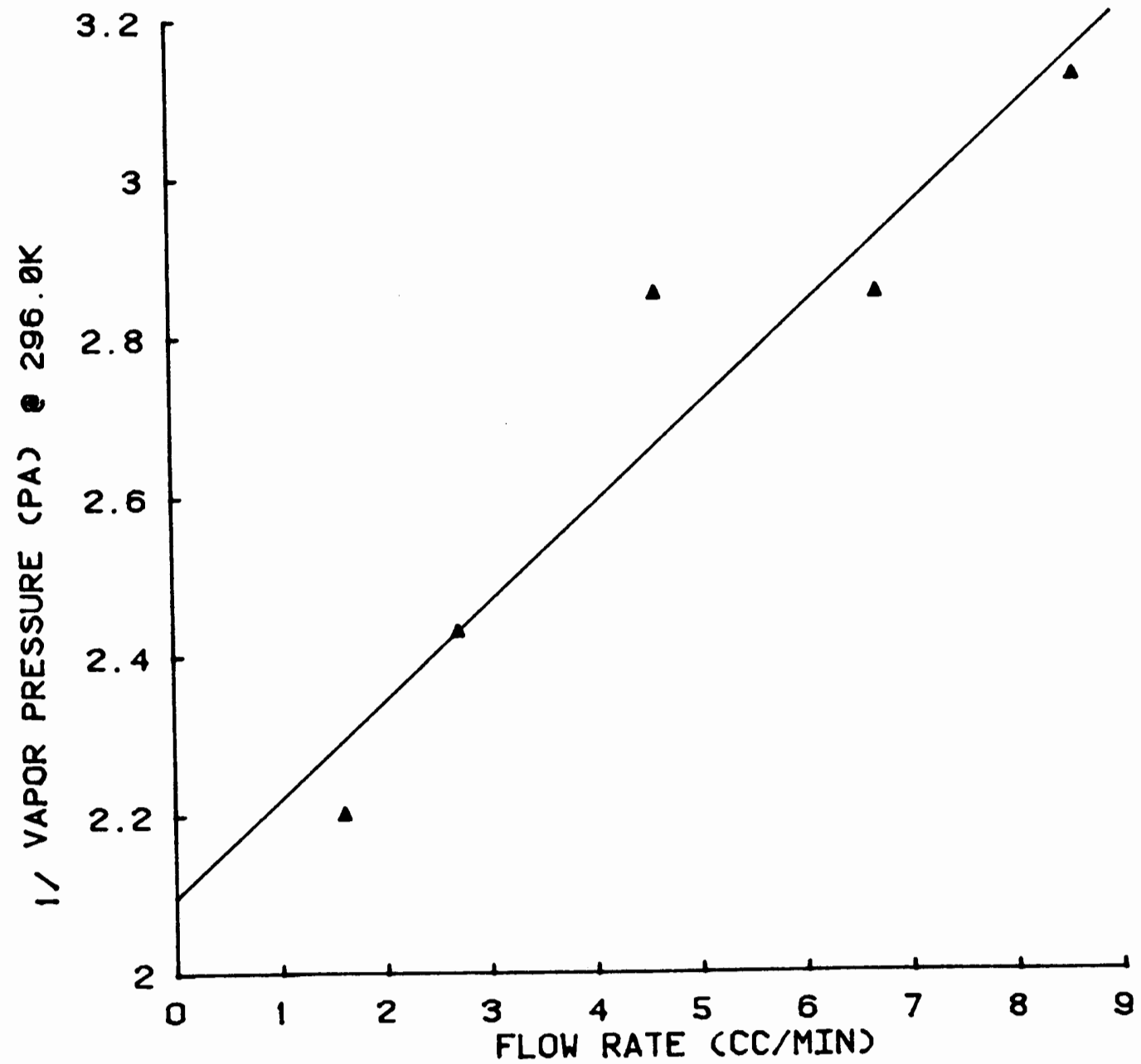

Figure 3. Benzoic acid-plot of 1 /vapor pressure vs. flow (3) $296.0 \mathrm{~K}$ 
29

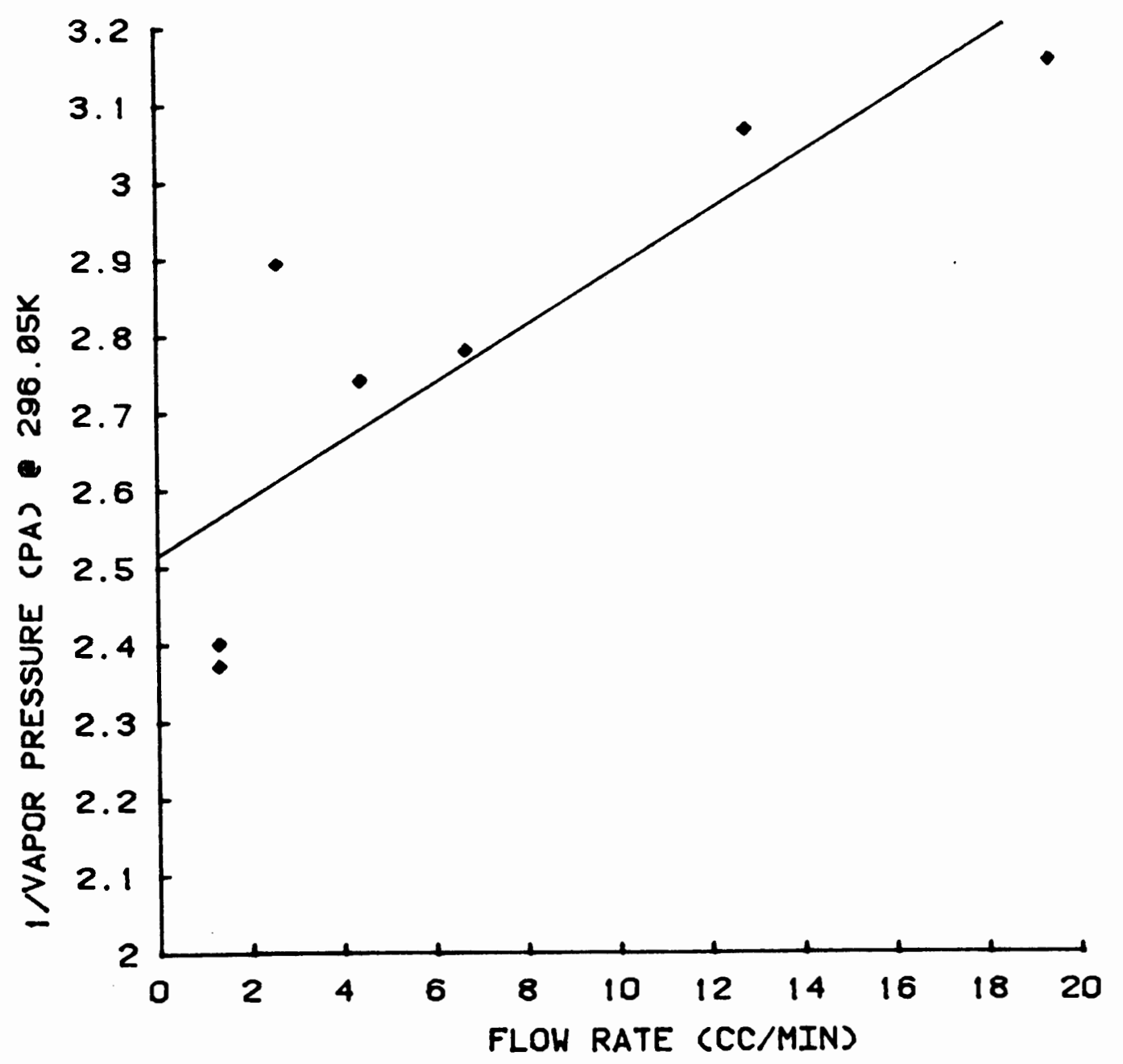

Figure 40 Benzoic acid-plot of 1/vapor pressure vs. flow (3) 296.0. K 
30

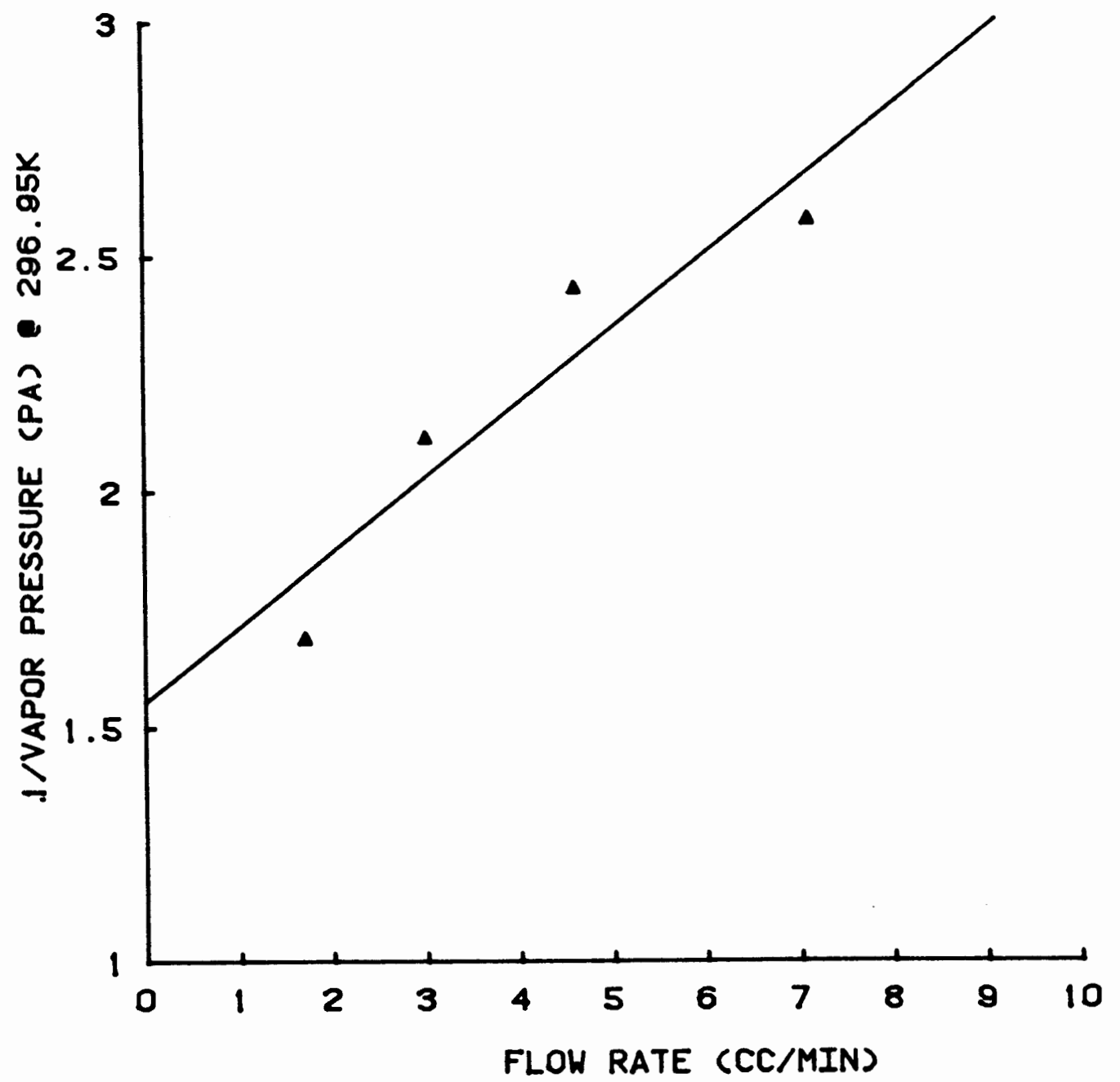

Figure 5. Benzoic acid-plot of I/vapor pressure vs. flow @ $296.95 \mathrm{~K}$ 


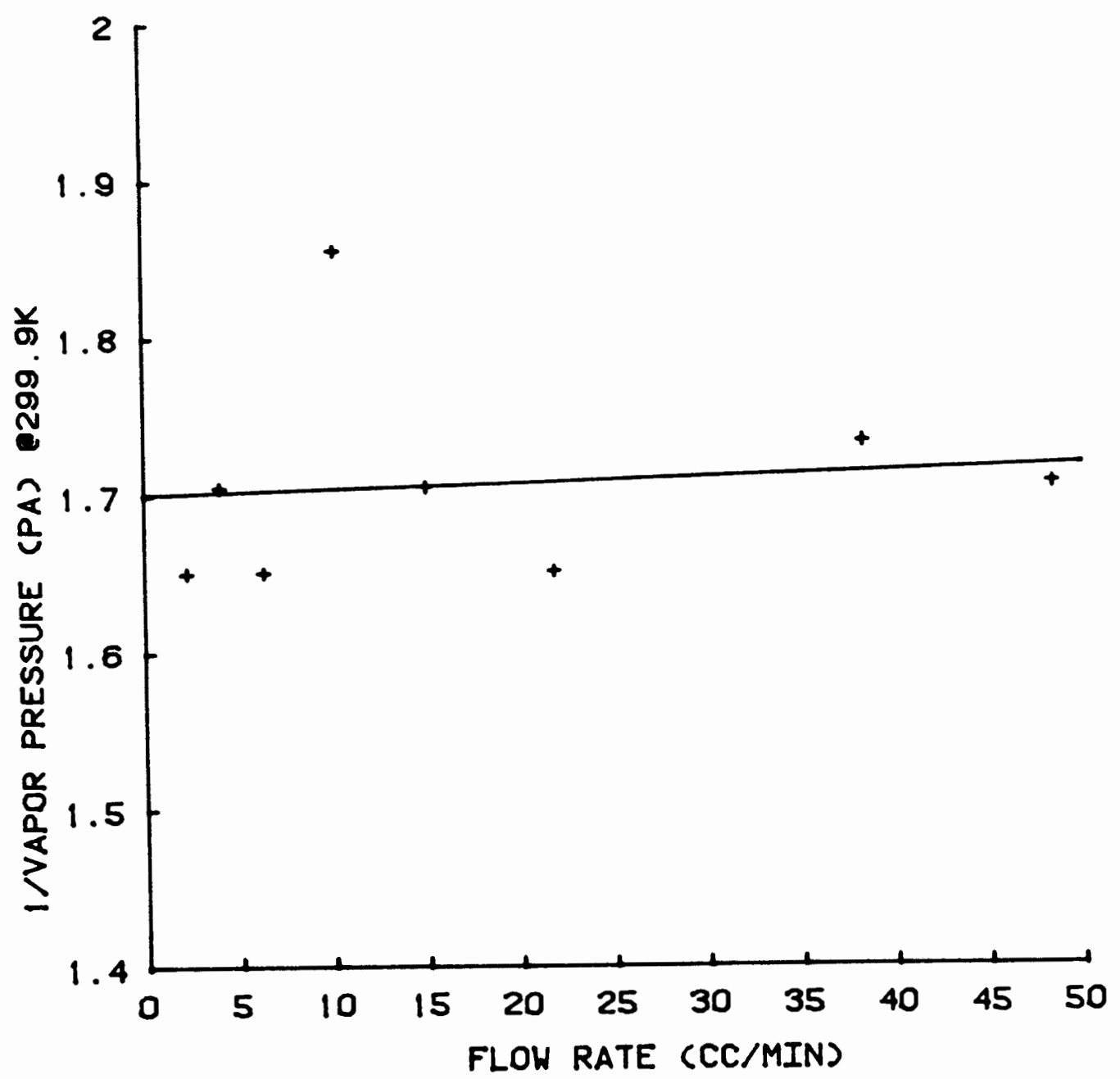

Figure 6. Benzoic acid-plot of $1 /$ rapor pressure vs. flow (a) 29.9.9X 


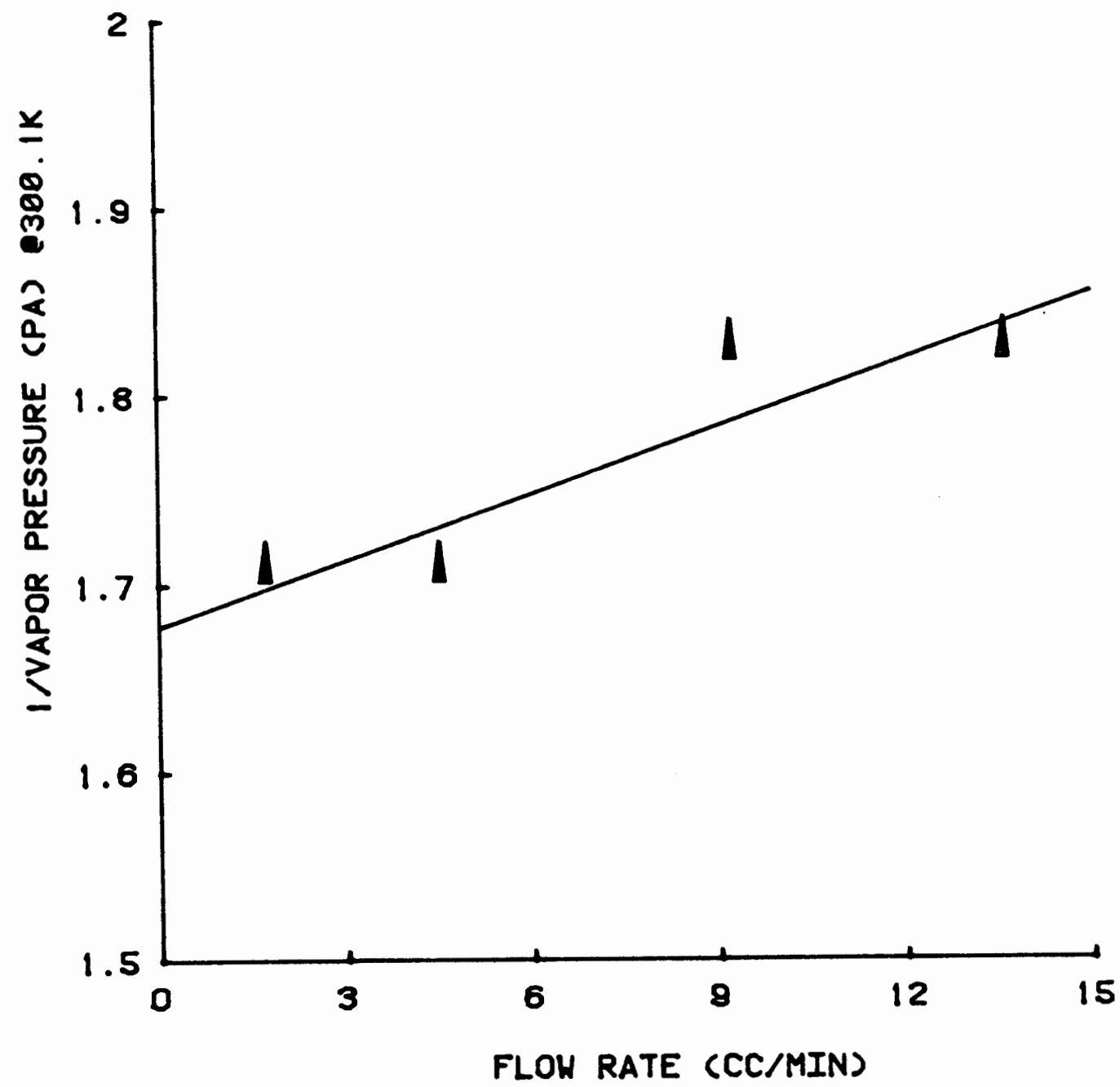

Figure 7. Benzolc acid-plot of I/vapor pressure vs. flow @300.IK 


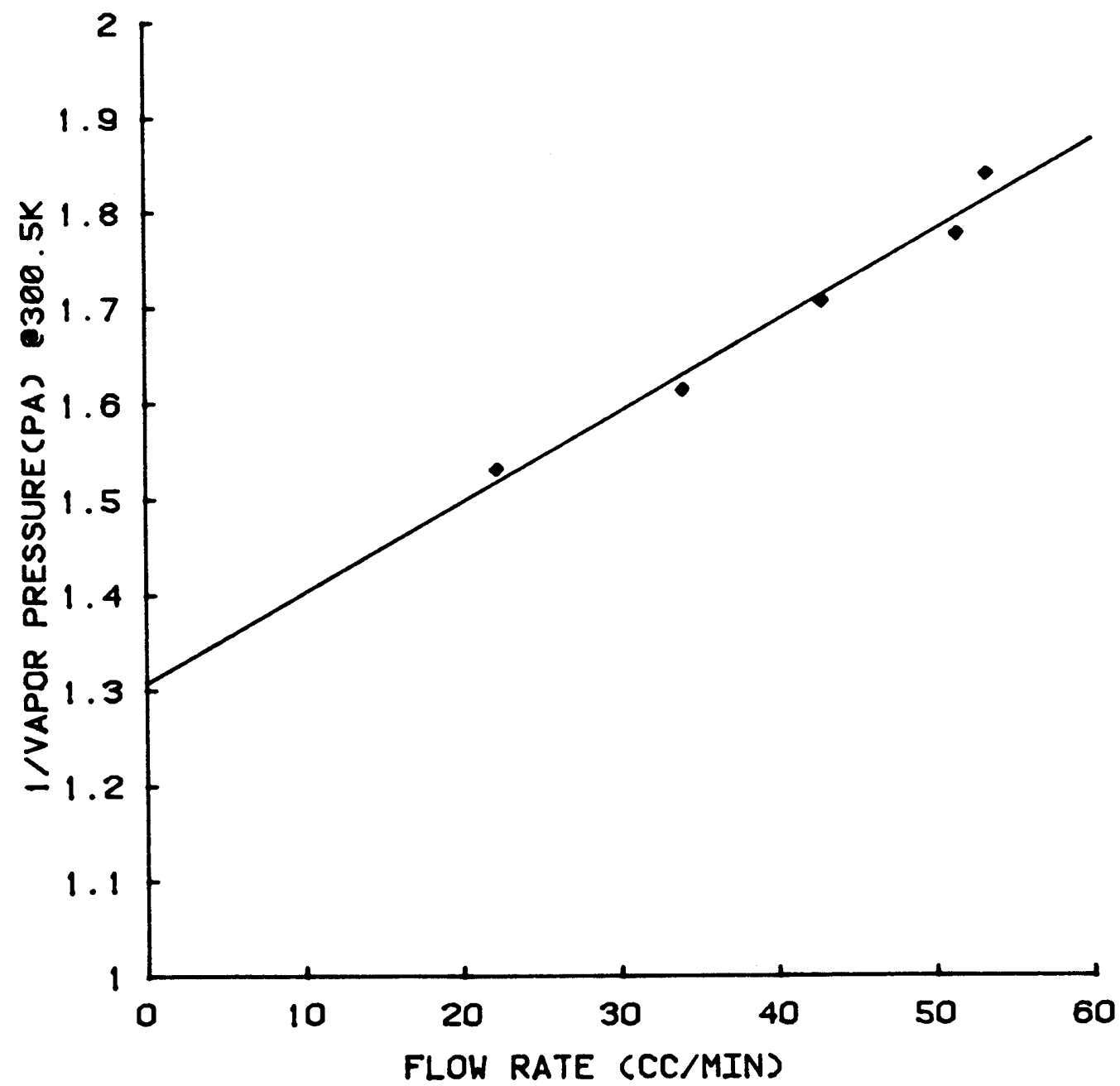

Figure 8. Benzoic acid-plot of I/vapor pressure vs. flow $300.5 \mathrm{~K}$ 


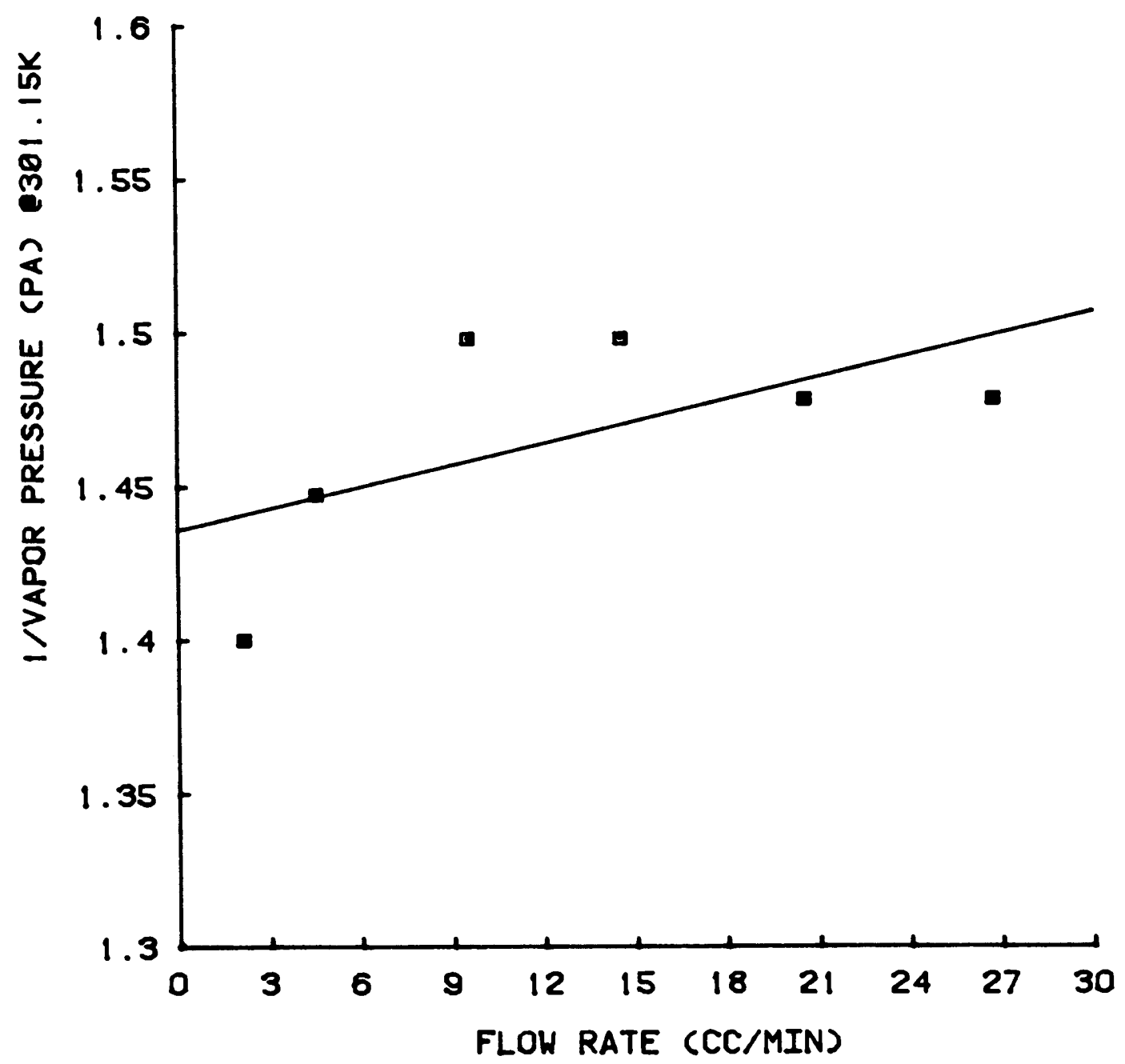

Figure 9. Benzoic acid-plot of 1/vapor pressure vs. flow $10301.15 \mathrm{~K}$ 


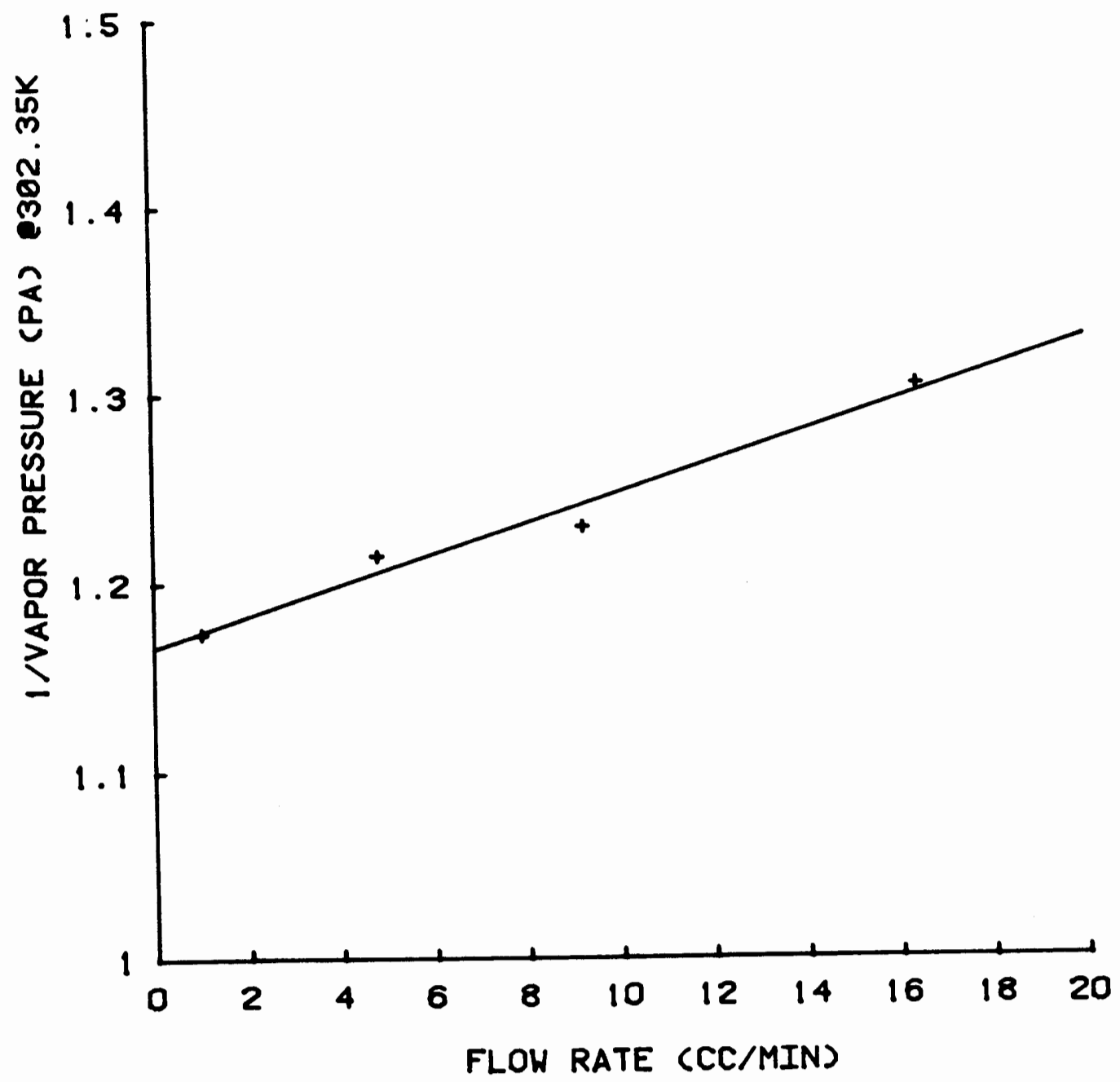

F1gure 10. Benzoic acid-plot of I/vapor pressure vs. flow @ $302.35 \mathrm{~K}$ 


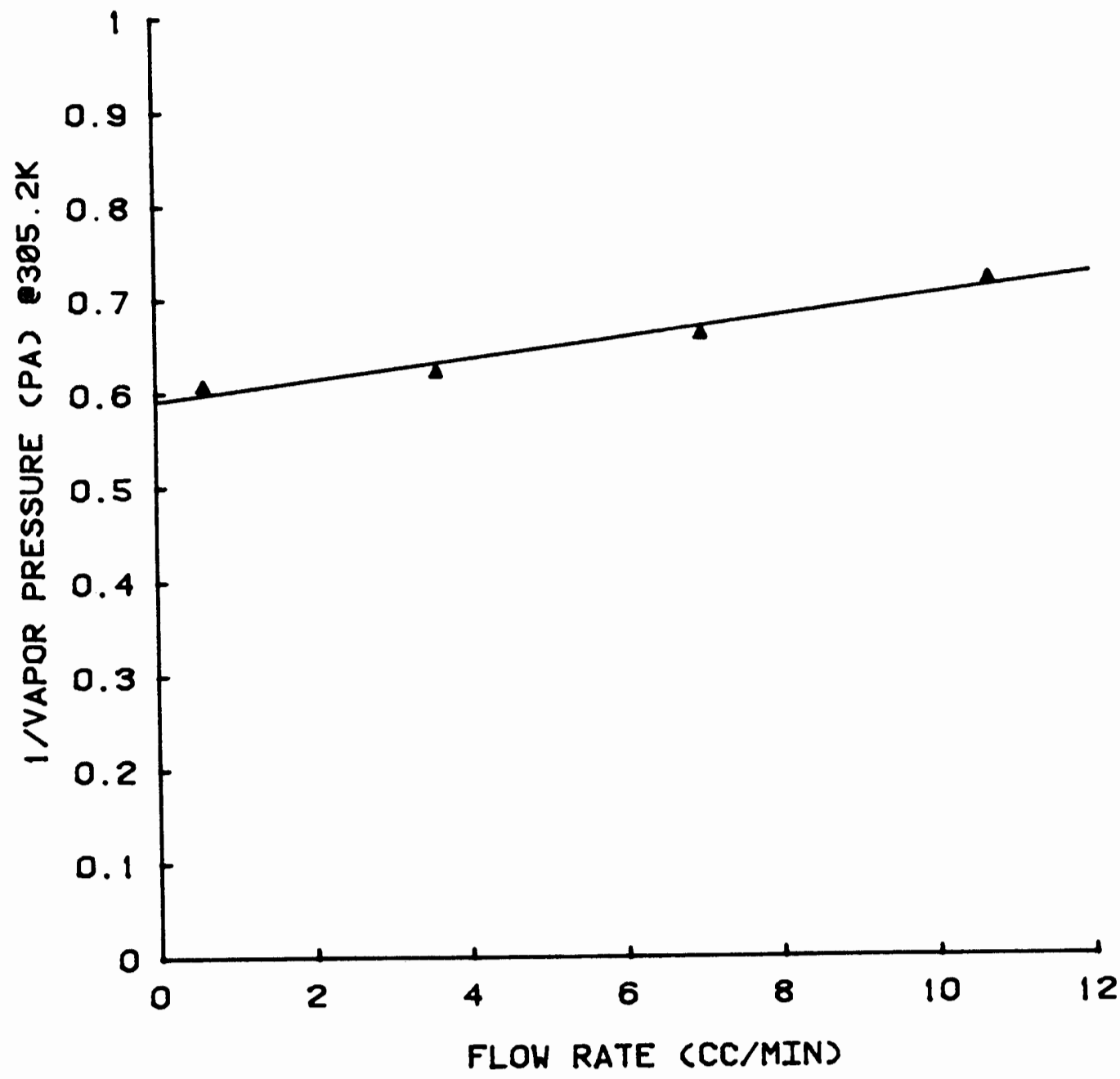

Figure 11. Benzoic acid-plot of 1/vapor pressure vs. flow @ $305.2 \mathrm{~K}$ 


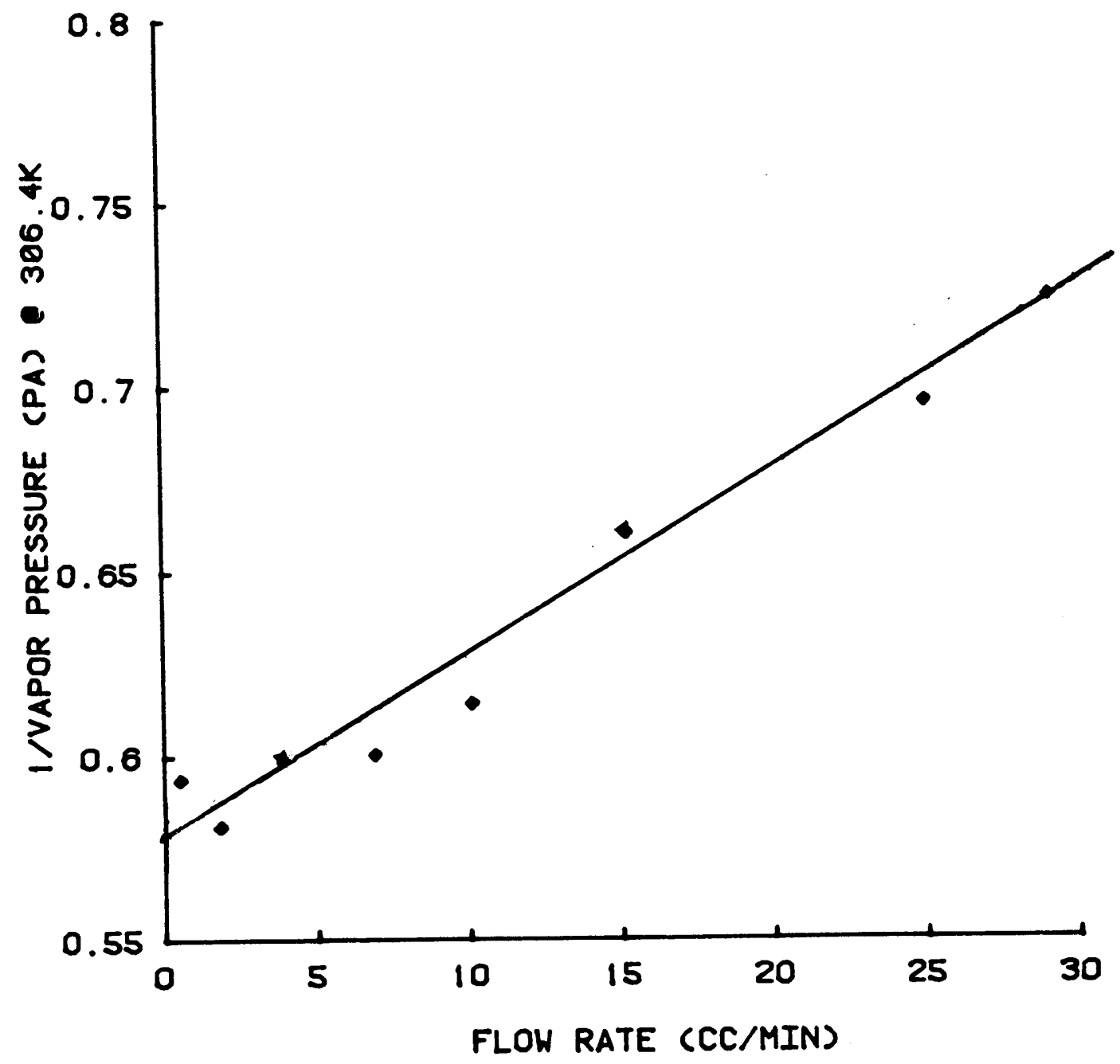

Figure 12. Benzoic acid-plot of 1/rapor pressure v8. flow $306.4 \mathrm{~K}$ 
data at $299.9 \mathrm{~K}$ differs by $34 \%$ from the nearest 1 iterature value (.83 versus $1.26 \mathrm{ppm}$.$) . The vapor pressures a 302 \mathrm{~K}$ differ by $31 \%$ (1.21 versus 1.76$)$. The values of 2.39 and $2.44 \mathrm{ppm}$. (o 305-306K from this study appear to fall in line with the adjacent lower and higher temperature values from van Ginkel's data. The error due to temperature variation in the current study can be visualized by changing vapor pressure with temperature in van Ginkel's data. For example, the difference from $297.76 \mathrm{~K}$ to $299.24 \mathrm{~K}(1.48 \mathrm{~K})$ is $24.8 \%$ in the vapor pressure of benzoic acid. This comes to an increase in vapor pressure of $16.7 \%$ per degree increase in temperature, not enough variation to completely bring this study's data into line with the literature. The $10 \%$ standard deviation in the calibration data draws the comparison closer.

Figure 13 is a plot of the natural logarithm of the vapor pressure data in Table III versus $1 / T$. The literature values are shown by rectangles, the current data by triangles. Van Ginkel's data approximate a linear plot. The current data had a large scatter. The errors previously mentioned account for this. The heat of sublimation determined from the slope of the best fit for the current data was $25.5 \mathrm{kcal} / \mathrm{mol}$ for all data and $22.9 \mathrm{kcal} / \mathrm{mol}$ excluding the data at $294.2 \mathrm{~K}$. The literature value of $21.5 \mathrm{kcal} / \mathrm{mol}$ from van Ginkel's data shows approximately a $20 \%$ difference from all of the current data, or $6 \frac{1}{2} \%$ from a 17 but the $294.2 \mathrm{~K}$ value. The best fits for the literature data and the current data minus the $294.2 \mathrm{~K}$ value differ by approximately $3 \frac{1}{2} \mathrm{~K}$ for the same value of in (vapor pressure).

NaphthaTene

Naphthalene's vapor pressure was investigated since many workers 


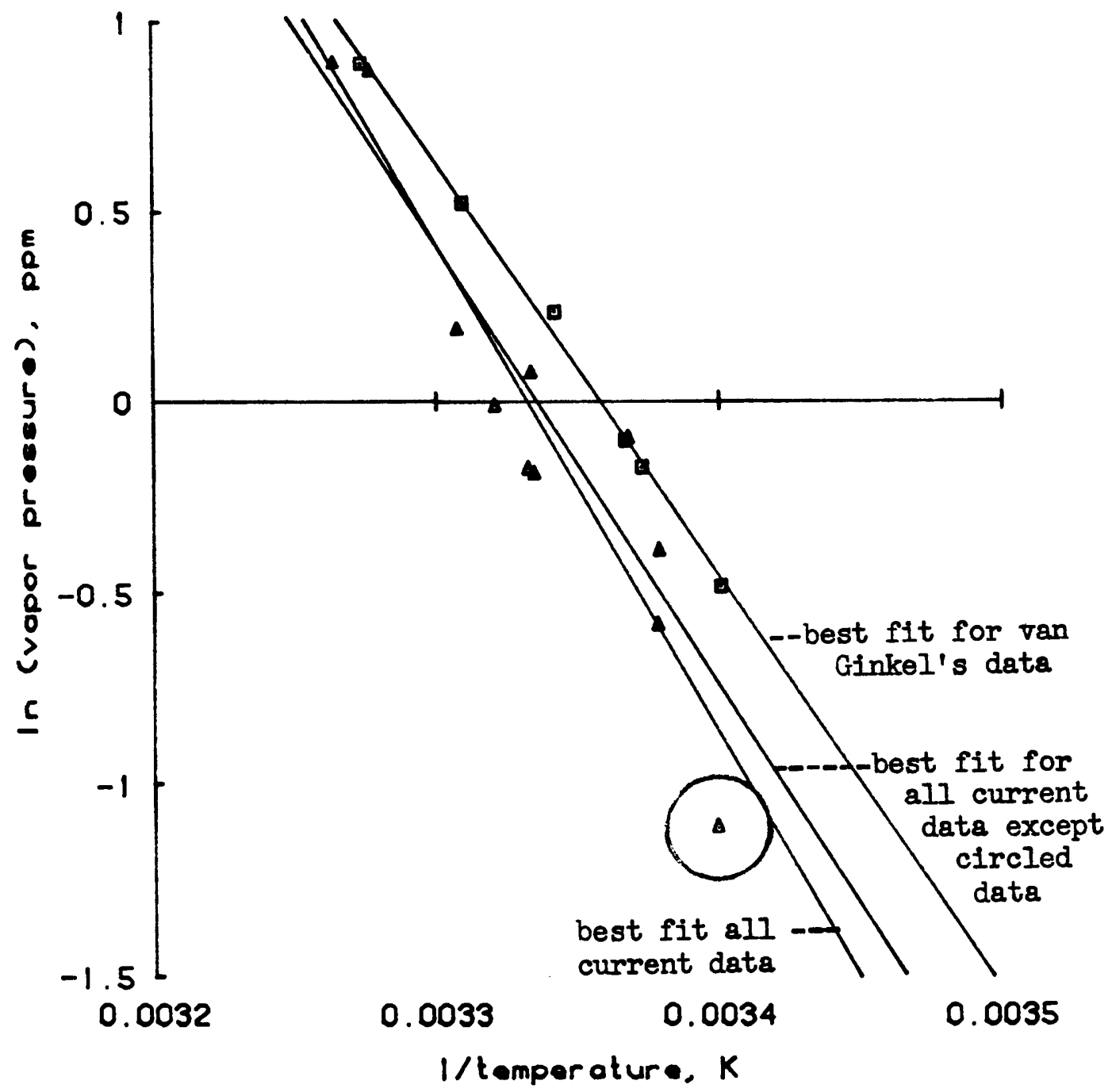

Figure 13. Benzoic acid-plot of In vapor pressure VS. I/I-current data and van Ginkel's data included. Triangles represent current data, squares represent van Ginkel's data. 
TABLE III

BENZOIC ACID VAPOR PRESSURES

\section{CURRENT METHOD}

\begin{tabular}{|c|c|c|c|c|c|c|c|}
\hline$R^{2}$ & Slope & $\mathrm{Pa} \times 10^{3}$ & Torr $\times 10^{3}$ & Ppm & $T / K$ & $\mathrm{Ppm}$ & Torr $\times 10^{3}$ \\
\hline .97 & 2.8 & 33 & .25 & .33 & $\begin{array}{l}294.1 \\
294.2\end{array}$ & .62 & .47 \\
\hline $\begin{array}{l}.91 \\
.71\end{array}$ & $\begin{array}{l}.12 \\
.04\end{array}$ & $\begin{array}{l}69 \\
57\end{array}$ & $\begin{array}{l}.52 \\
.56\end{array}$ & $\begin{array}{l}.68 \\
.43\end{array}$ & $\begin{array}{l}296.0 \\
296.05 \\
296.52\end{array}$ & .84 & .64 \\
\hline \multirow[t]{2}{*}{.88} & .16 & 92 & .69 & .91 & $\begin{array}{l}296.95 \\
297.04\end{array}$ & .90 & .69 \\
\hline & & & & & 297.76 & 1.01 & .76 \\
\hline $\begin{array}{l}.01 \\
.83\end{array}$ & $\begin{array}{l}.0003 \\
.01\end{array}$ & $\begin{array}{l}84 \\
85\end{array}$ & $\begin{array}{l}.63 \\
.64\end{array}$ & $\begin{array}{l}.83 \\
.84\end{array}$ & $\begin{array}{l}299.24 \\
299.9 \\
300.1\end{array}$ & 1.26 & .96 \\
\hline .97 & .009 & 109 & .82 & 1.08 & 300.5 & & \\
\hline .37 & .002 & 100 & .75 & .99 & $\begin{array}{l}301.15 \\
302.18 \\
302.20\end{array}$ & $\frac{1.68(1.71)^{*}}{1.76}$ & ${ }^{\star} \begin{array}{l}28(1.3)^{\star} \\
1.34\end{array}$ \\
\hline \multirow[t]{2}{*}{.97} & .008 & 123 & .92 & 1.21 & 302.35 & & \\
\hline & & & & & 304.51 & 2.13 & 1.62 \\
\hline .96 & .01 & 242 & 1.8 & 2.39 & 305.2 & & \\
\hline \multirow[t]{2}{*}{.97} & .005 & 248 & 1.9 & 2.44 & 306.4 & & \\
\hline & & & & & 307.15 & 3.14 & 2.39 \\
\hline
\end{tabular}

\section{VAN GINKEL}


had obtained values in the vicinity of $300 \mathrm{~K}(5,16,17,20,22,33$, 29-42), and Sinke (17) and Ambrose (23) have pointed out the need for a stable standard such as naphthalene for calibration of instruments and procedures for measuring low vapor pressures.

Figures 14-18 are the 1/vapor pressure versus flow rate plots for naphthalene, from 297.8-307.0K. Figures 16-18, representing the higher temperatures used, show the more nearly linear plots. The trend in slopes is the same as it was for benzoic acid. At higher temepratures the slopes decreased for the first four plots. The plot at $307.0 \mathrm{~K}$ was the anomaly, having the largest slope of all. The plot at $302.0 \mathrm{~K}$ was the only one with a correlation coefficient less than $.90(.83)$. The significant difference in the trial run producing the $307.0 \mathrm{~K}$ reading from the others was the fact that it was performed on a similar size sample (approximately 0.1 g.) but 8 months later. Temperature control was a factor in the determinations, as it was with benzoic acid. Surface area differences may also have had an affect.

Table IV presents the vapor pressure from Figures 14-18 compared with literature values from various experiments. Included are the correlation coefficients and slopes of the best fit lines for each of the current data plots.

From Table IV the slopes of the previous plots differ at most by only one order of magnitude. The first four data are closely related in two groups. The first two values are centered about $298 \mathrm{~K}$, and the next two are grouped about $302 \mathrm{~K}$. The average of the values about $298 \mathrm{~K}$ in this study is $11.0 \mathrm{pa} . ;$ the literature values $0298 \mathrm{~K}$ average $11.1 \mathrm{pa}$. For the second group o $302 \mathrm{~K}$, the average of the current data is $15.1 \mathrm{pa}$. 


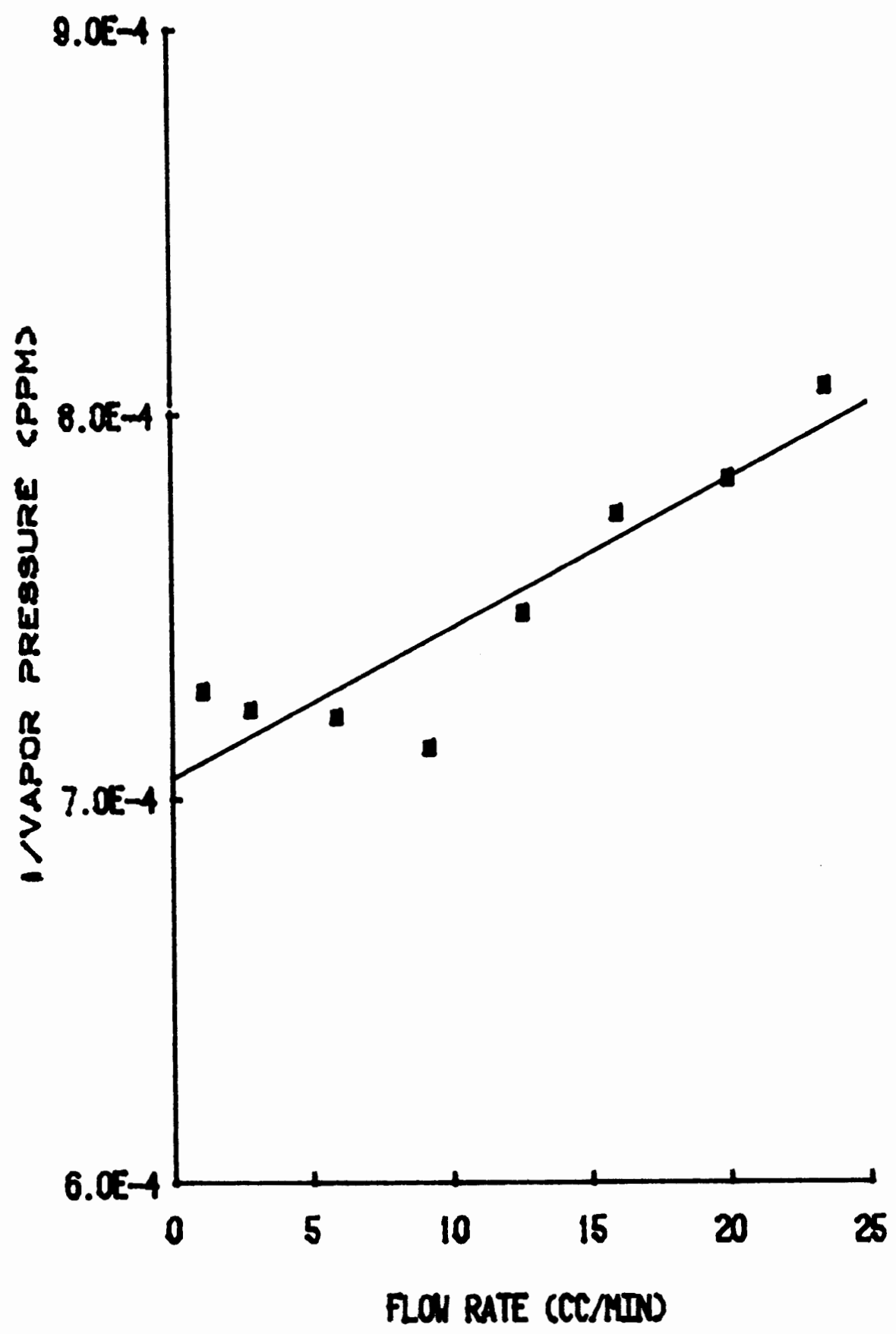

Figure 14. Naphthalene -plot of $1 /$ vapor pressure v8. flow ब $297.8 \mathrm{~K}$. 


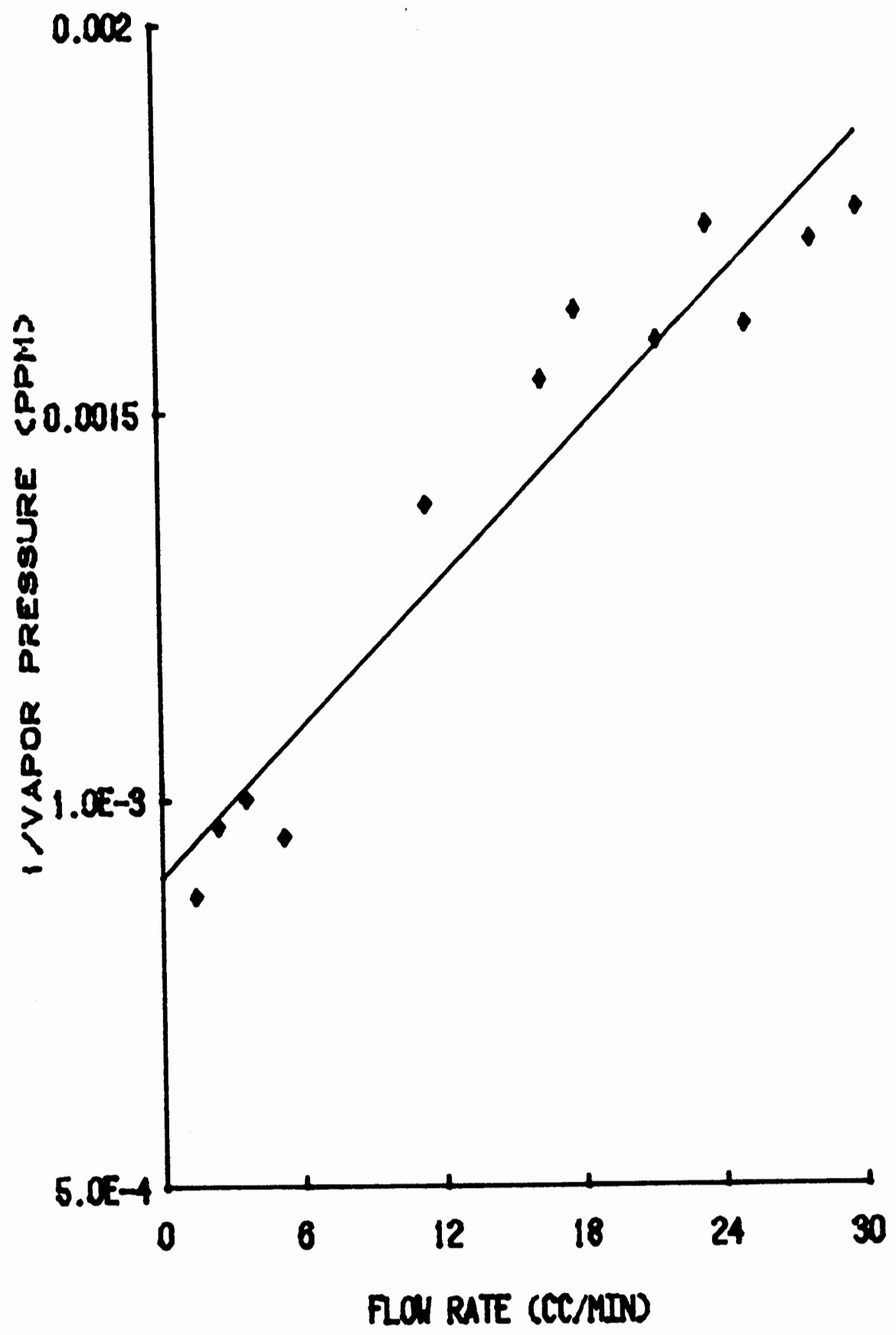

Figure 15. Naphthalene-plot of 1 /vapor pressure vs. flow (ब298.65K. 
44

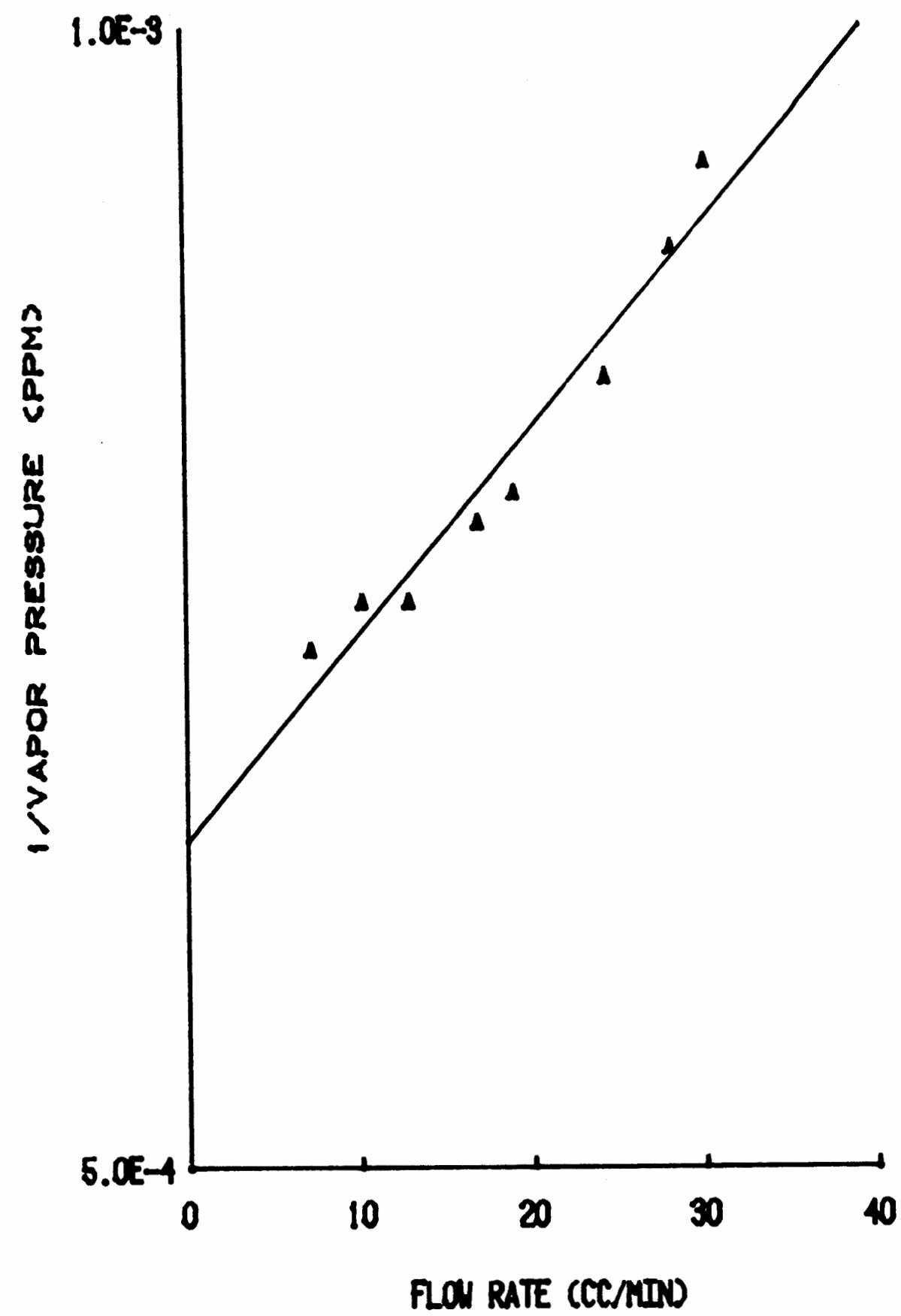

Figure 16. Naphthalene-plot of 1 /vapor pressure vs. flow ब301.45\%. 


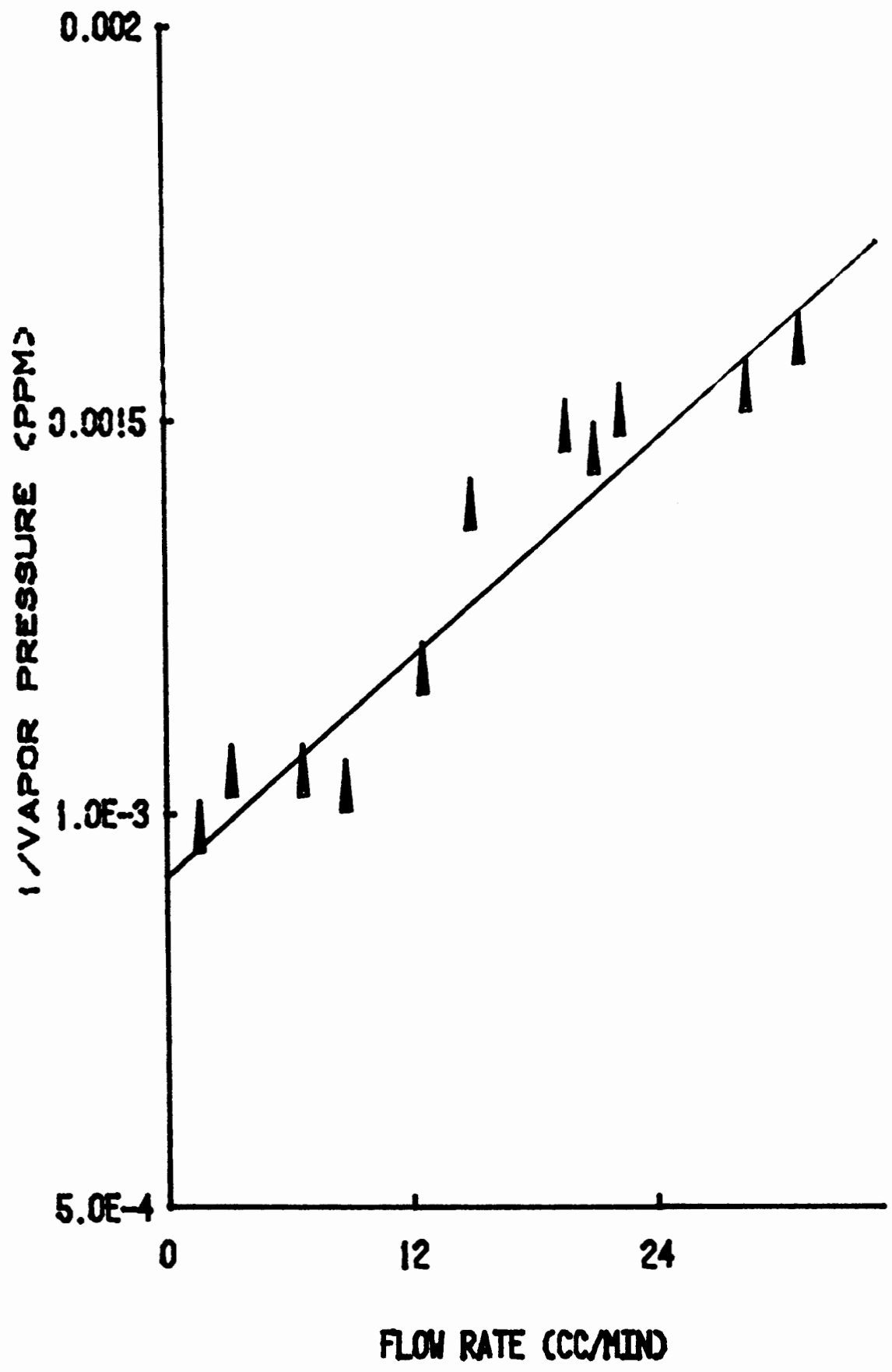

Figure 17. Naphthalene-plot of 1/vapor pressure vs. flow ब] $302.0 \mathrm{~K}$. 


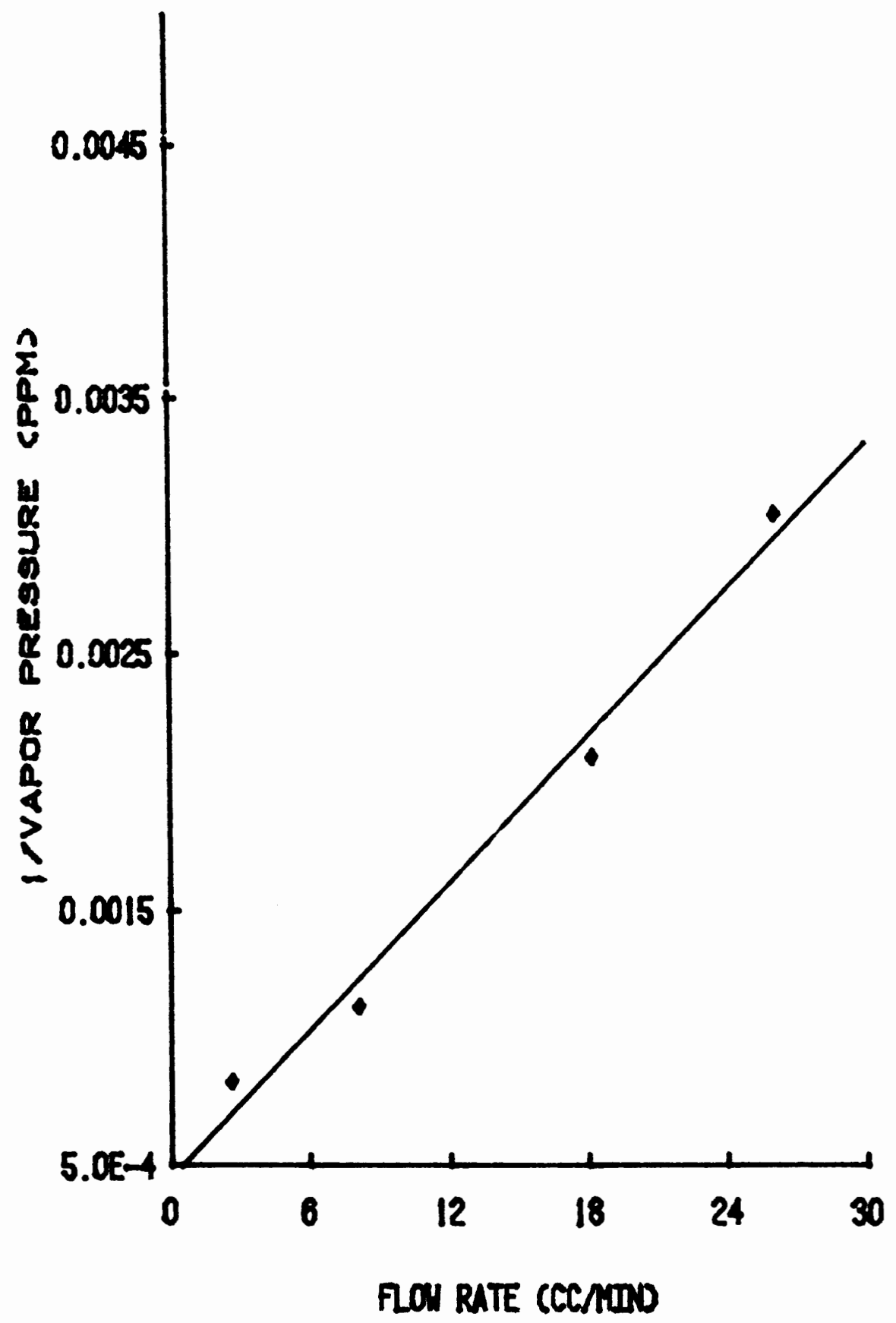

Figure 18. Naphthalene-plot of 1/vapor pressure vs.flow (1) 307.0K. 


\section{TABLE IV}

NAPHTHALENE VAPOR PRESSURES

Current Method

Literature

$\mathrm{R}^{2}$ Slope Ppm. Torr Pa. T/K Pa.

$$
\begin{array}{ll}
292.8 & 6.53,6.56(16) \\
293 & 8.64(33), 8.53(22) \\
293.24 & 6.93(23) \\
293.25 & 6.95(23) \\
293.7 & 7.12(18) \\
294.1 & 7.47,7.71(16) \\
296.2 & 9.52,9.53(16)
\end{array}
$$

$\begin{array}{llllll}.92 & 3.19 \times 10^{-5} & 111 & .085 & 11.27 & 297.8\end{array}$

$$
298.15 \quad 10.93(17)
$$

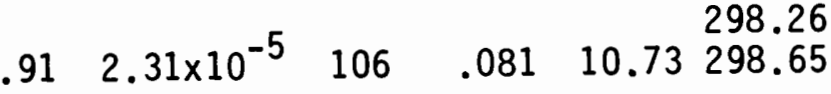

$$
\begin{array}{ll}
299.15 & 12.65,12.52(16) \\
299.40 & 12.59(5) \\
300 & 13.09(17)
\end{array}
$$

$\begin{array}{llllll}.93 & 8.44 \times 10^{-6} & 156 & .12 & 15.76 & 301.45\end{array}$

$\begin{array}{llllrl}.83 & 3.89 \times 10^{-6} & 143 & .11 & 14.53 & 301.6 \\ 303\end{array}$ $16.37,16.35,16.68(16)$

$$
\begin{array}{ll}
303 & 23.60,21.73(33) ; 21.86(22) ; \\
& 18.67(39) ; 21.33(41) ; 17.33 \\
303.29 & (42) ; 16.00(40) ; 16.00(20) \\
& 18.45(23) \\
304.85 & 20.00(5) \\
305.5 & 23.33,23.45(16)
\end{array}
$$

$\begin{array}{llllll}.98 & 9.53 \times 10^{-5} & 218 & .17 & 22.08 & 307.0\end{array}$

$$
\begin{array}{ll}
308.17 & 28.95(23) \\
310.4 & 35.61,37.06(16) \\
313 & 44.00(20) ; 42.66(39) ; 40.00 \\
& (40) ; 52.00(41) ; 44.00(42)
\end{array}
$$


The literature average here is $16.5 \mathrm{pa}$. , showing an $8 \%$ difference. The remaining value from the current data, at $307.0 \mathrm{~K}(22,08 \mathrm{pa}$.$) falls$ well within $1 \%$ of the average of the three literature values o $305 \mathrm{~K}(22.26$ pa.). The closest literature value, at $308.17 \mathrm{~K}$ (28.95 pa.), differs by $24 \%$. An indication of the variation in vapor pressure with temperature in the literature is shown in the data for $298.15 \mathrm{~K}$ (10.93 pa.) and the average value for $299.15 \mathrm{~K}$ (12.59 pa.). This difference is $1.66 \mathrm{pa} . / \mathrm{K}$, or an increase of $15 \%$ per degree rise. Therefore, a variation of 1 degree in temperature in the current study during the course of a trial run can explain the differences between literature values and current data.

Figure 19 is a plot of the data in Table IV. The inset shows the current data by itself. Note the fact that the current data follow the best fit line closely, while the literature values show the scatter seen in the current data for benzoic acid. The current data approach the literature values at lower temperatures. This fact supports the assumption that the temperature variation, found to be greatest at high temperatures, within experimental runs caused discrepancies easily corrected by adequate temperature control.

The heat of sublimation derived for the literature data was 16.9 $\mathrm{kcal} / \mathrm{mol} ; 14.3 \mathrm{kcal} / \mathrm{mol}$ was found with the current data, a difference of approximately $15 \%$.

\section{Benzophenone}

Two trials at $298.0 \mathrm{~K}$ and $303.8 \mathrm{~K}$ were run with benzophenone as a check of the agreement with van Ginkel's data (19). He had used an effusion method to determine the vapor pressures of benzoic acid and 


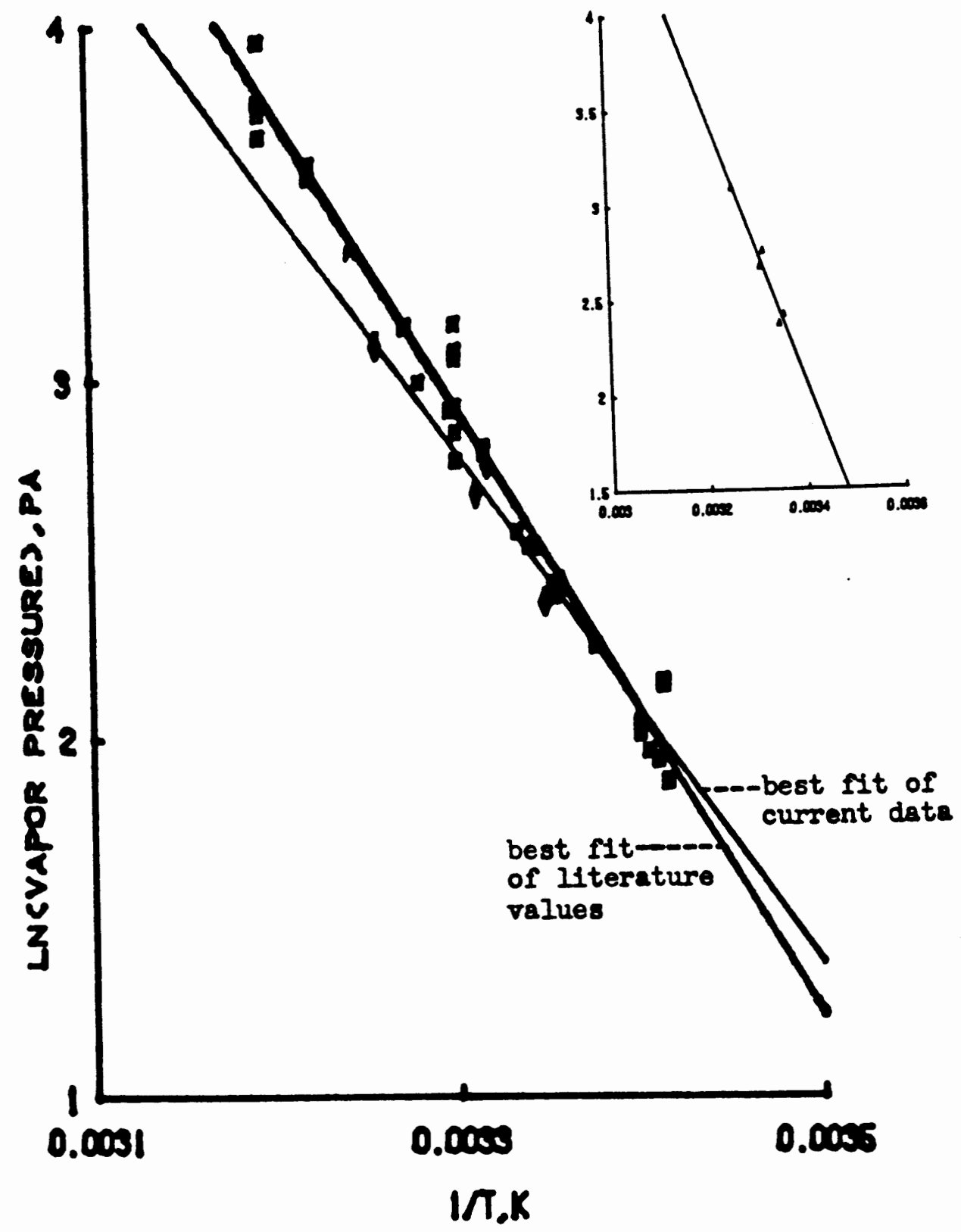

F1 gure 19. Nephthalene-plot of $\ln$ (vapor pressure) V8. II-current data and I1terature values included. Diemonds represent current data, squares represent Hiterature relues. Inset is the current date alono, with the best fit applied. 
benzophenone. Both compounds have vapor pressures in the millitorr range at ambient temperatures. Figures 20 and 21 display the 1 /vapor pressure versus flow rate plots for benzophenone. Figure 20 appears to show an inverse relationship between flow rate and 1/vapor pressure. The data represent a $10 \%$ change from lowest to highest flow rate used for the vapor pressure measurements. As with previous trials, this can be attributed to the lack of temperature control. Figure 21 appears to approximate saturation conditions at the flow rates studied, $2-10 \mathrm{cc} / \mathrm{min}$.

Table $V$ shows the data of this method compared with three values from van Ginkel (19) and two from de Kruif (31).

\section{TABLE $V$}

BENZOPHENONE VAPOR PRESSURES

Current Method

Torr $\times 10^{3}$

$$
.608
$$

1.55
Ppm.

.80

80

2.04
$\mathrm{Pa} . \times 10^{3} \quad \mathrm{~T} / \mathrm{K}$

$$
296.83
$$

$81.1 \quad 298.0$

303.71

$206.7 \quad 303.8$

305.00

305.74

307.73 van Ginkel (19) de Kruif (31)

$$
\mathrm{Pa} . \times 10^{3} \quad \mathrm{~Pa} . \times 10^{3}
$$

87.9

193.5

222.9

226

292

It can be seen from Table $V$ that the current data from the $298.0 \mathrm{~K}$ trial are $8 \%$ lower than the $296.83 \mathrm{~K}$ value from van Ginkel's experiment. This was also the data plotted in Figure 20, which had negative slope for its best fit line. The current data at 303.8 differed in a positive direction from the value at $303.71 \mathrm{~K}$ in van Ginkel's study by $8 \%$, we 11 


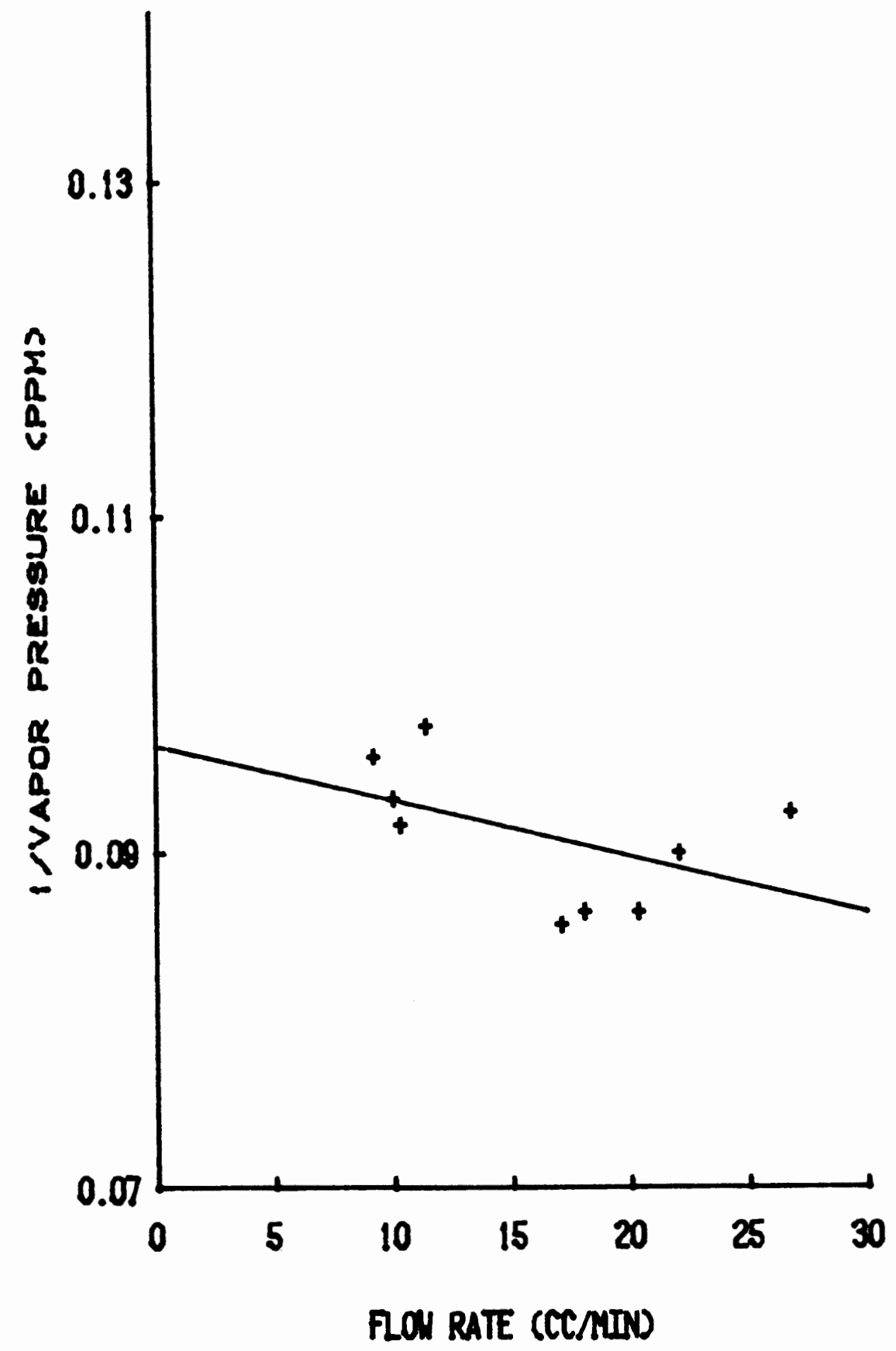

Figure 20. Benzophenone-plot of I/vapor pressure vS. flow (398.0K. 


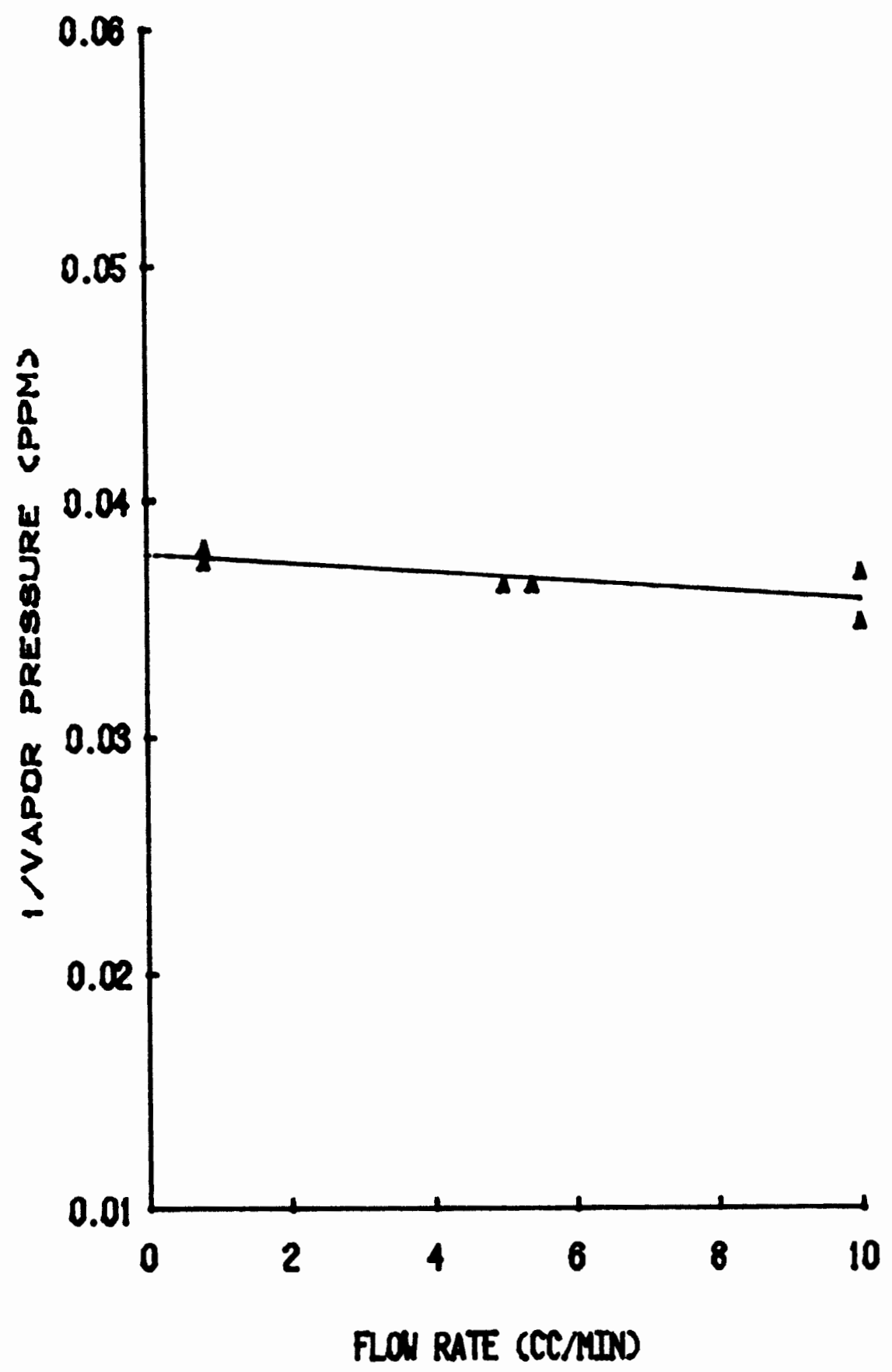

Figure 2l. Benzophenone-plot of $1 /$ vapor pressure $\nabla 8$. 110w ब 303.8K. 
within the experimental error.

Figure 22 is a plot of the literature values with the best fit line drawn through the data. The current data, symbolized by triangles, depict the close fit of the higher temperature value from the current data and the disparity of the lower temperature value from the literature best fit line.

Phenylhydrazine

Two trials were run to measure the vapor pressure of phenyhydrazine, the only liquid tested, at 293.05K and 294.3K. No literature values were found for direct measurement of the vapor pressure of phenylhydrazine at ambient temperatures. Phenylhydrazine was reported as having a vapor pressure of 0.0278 torr o $198 \mathrm{~K}(24)$. This measurement was accomplished by an equation-fitting technique.

Figures 23 and 24 show the current data plotted as 1/vapor pressure versus flow rate. Both approximate linear plots. The difference in slops is attributable to the temperature variation during the trials $\left(3 \times 10^{-3}\right.$ versus $.8 \times 10^{-3}$, respectively).

Table VI compares the current data, including slopes of the best fit lines from Figures 23 and 24.

TABLE VI

PHENYLHYDRAZINE VAPOR PRESSURES

$T / K$

293.05

294.3
$\mathrm{Pa}$.

1.90

2.21

$\frac{\text { Ppm. }}{18.80}$

21.83
Torr

.0142

.0166
Slopes

$3 \times 10^{-3}$

$.8 \times 10^{-3}$ 
54

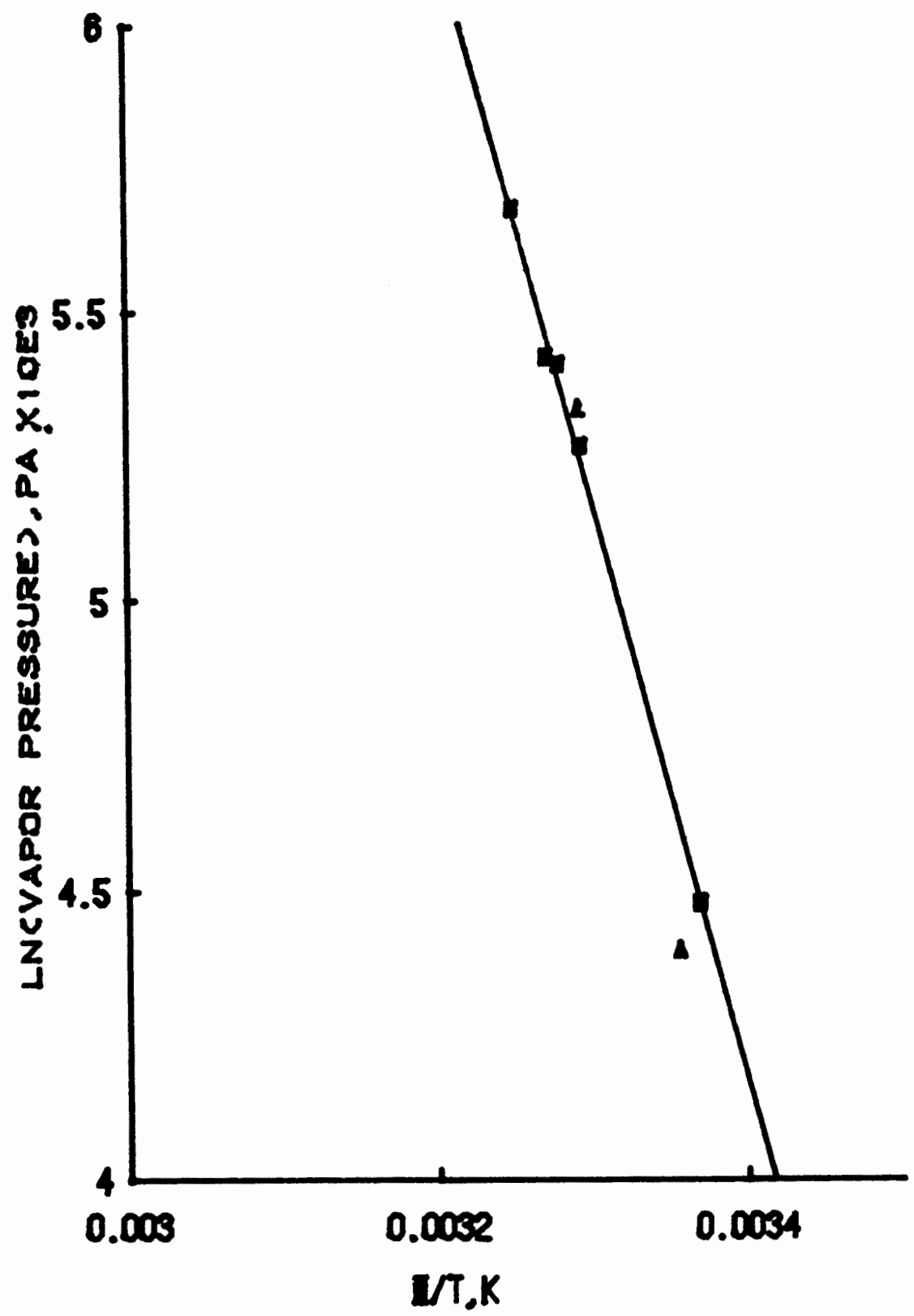

Figure 22. Benzophenone-plot of In( vapor pressure) vs. I/1-curreñt data and literature values included. Mriangles represent current data, squares represent literstire values. Solid line is best fit for literature valres. 


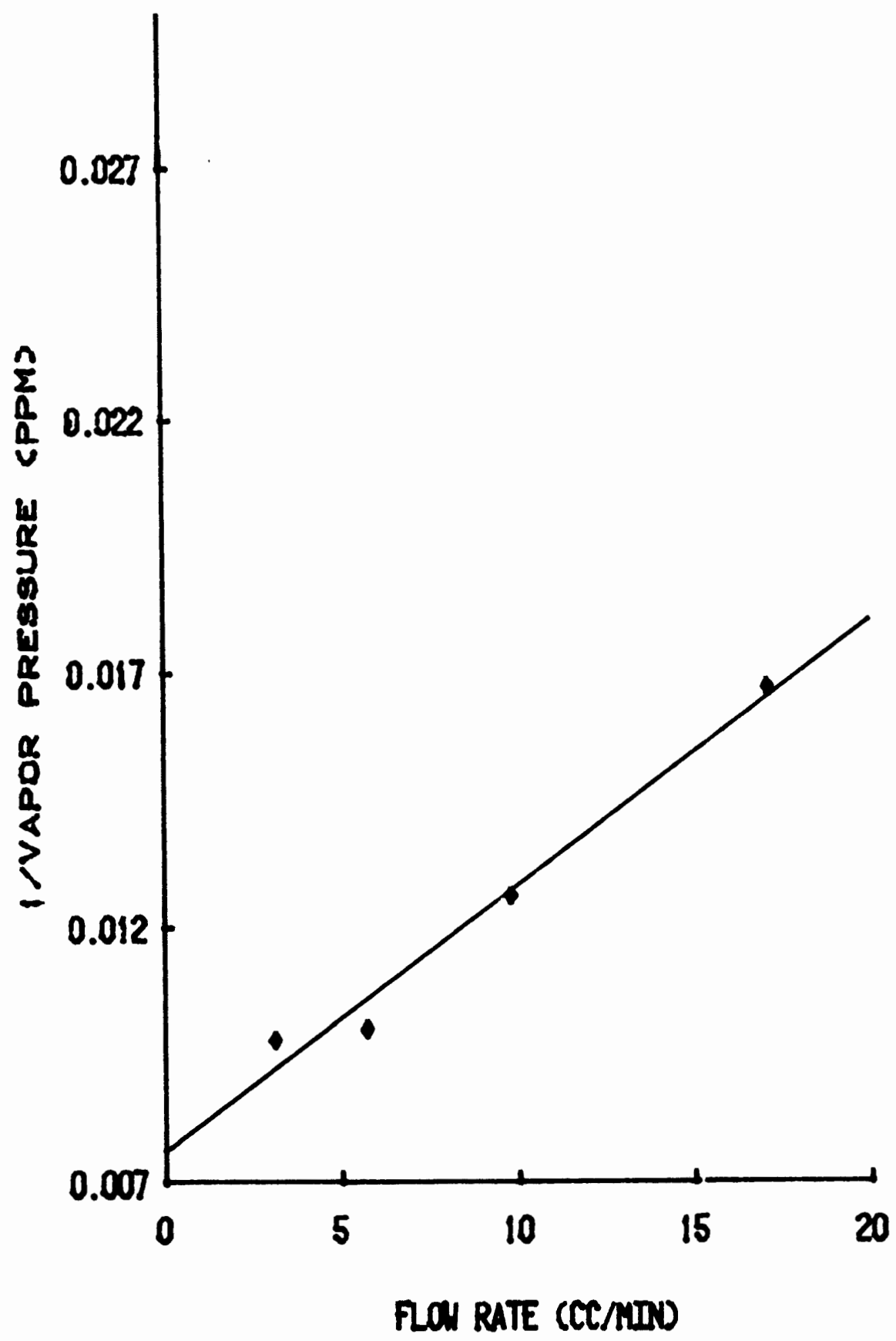

Figure 23. Phenylhydrazine-plot of 1 /vapor pressure जs. IIO (29) 29.3K. 


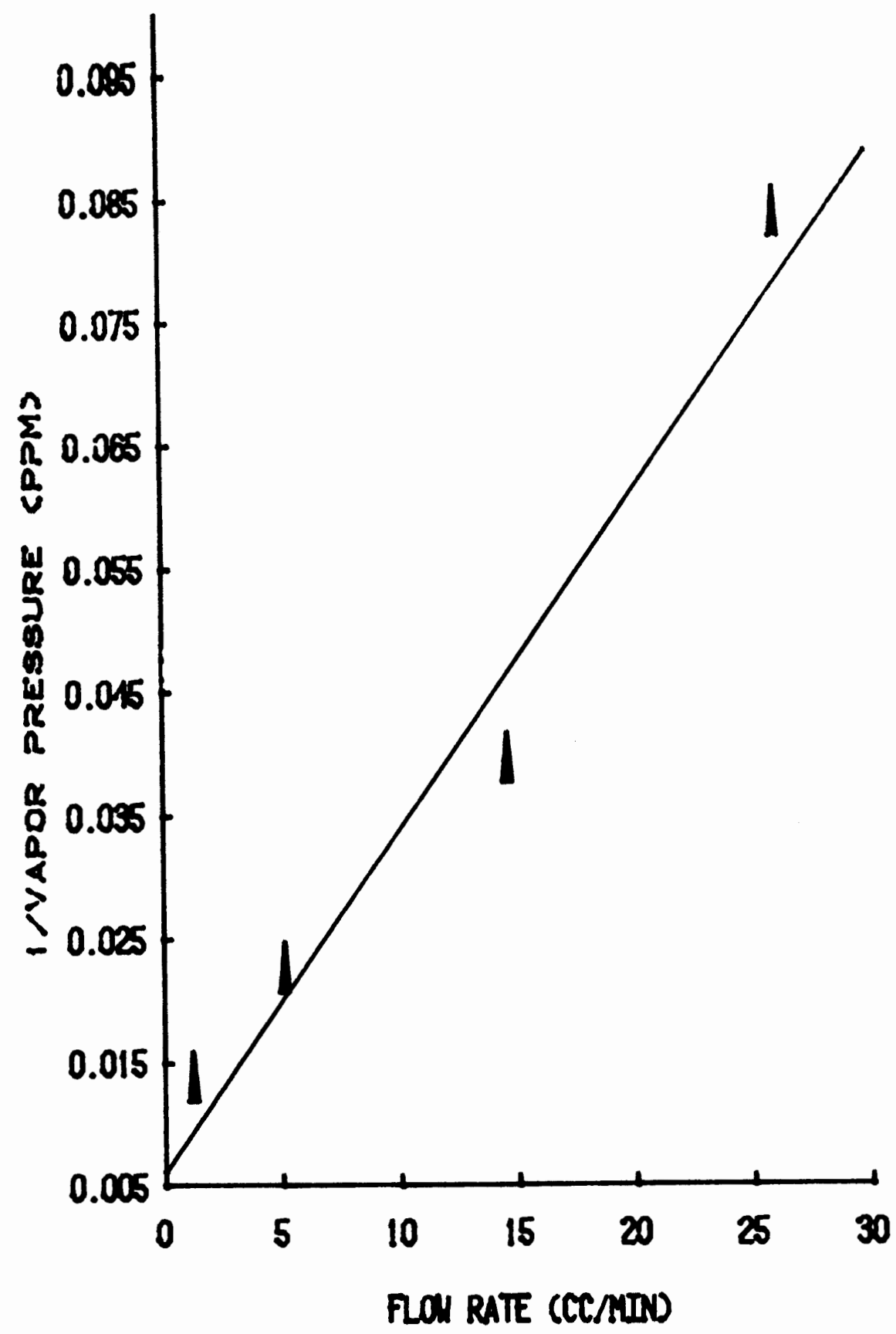

Figure 24. Phenylhydrazine-plot of 1 /vapor pressure जs。 flow (1) 293.05K. 


\section{GENERAL DISCUSSION}

\section{Systematic Error}

As was shown previously in the literature values for benzoic acid, temperature variations of 1 degree can generate a difference of as much as $17 \%$ in the vapor pressure measurements. Baseline error was expected to be as much as $1 \%$. The calibration error was approximately $10 \%$. Add to this approximately $2.5 \%$ error in the measurement of peak height and $10 \%$ for the measurement of peak widths at $\frac{1}{2}$ peak height of $0.10 \mathrm{~cm}$.

The measurements in this experiment were negligibly influenced by detector error, since the attenuation used was always greater than $x 4$ for vapor pressure measurements, well out of the range where flame noise affected readings. Drift in the signal was negligible during peak development on the chart. Using the square root of the sum of the squares of the errors as a simple approximation to the overall systematic error, the error was $\pm 21 \%$.

\section{Problems}

Temperature. As stated in the results of vapor pressure measurement in this chapter, temperature varied with room temperature variations. Enclosing of the sample cell in a temperature-controlled jacket of glass with circulating water would reduce errors in evaluating the data relative to literature values and also make the readings self-consistent. Comparing the literature values for vapor pressure changes with temperature shows as much as a $17 \%$ change in vapor pressure per degree Kelvin.

Impurities. In the method used, the baseline as measured by the 
signal due to the $\mathrm{CO}_{2}$ line was subtracted from that of the TC line, if the former was greater than $1 \%$ of the latter. This allowed a corresponding error to exist. A method which would improve on this would be the employment of the gas chromatographic column as a separator of all carbon sources before the combustion chamber in this system. Hence, one could measure total carbon on any given trial from each individual component of the gas stream. Problems, however, arise in this alternative due to the need for selection of the proper carrier gas for separation and combustion.

\section{Applicability of the Method}

This method was composed of four main tools used in the direct determination of vapor pressures in the $10^{-2}$ to $10^{-6}$ torr range. Due to either a lack of substantial literature that corroborated a particular standard value, or, in the case of phenylhydrazine and benzoic acid, the absence of as many as two direct measurements at ambient temperatures, accuracy was difficult to assess.

The four tools referred to were: a) a variable flow gas saturation method, b) a flame ionization detector, c) a kinetic model developed which has a basis in the theory of the charging of a sample onto a gas chromatographic column $(36,37)$, and d) an oxidation oven which converts all carbon atoms in a sample to $\mathrm{CO}_{2}$.

As opposed to the numerous total saturation methods that have been used, this method needed only a few measurements at different flow rates in order that the saturated vapor pressure of a substance could be determined by extrapolation to zero flow using kinetic 
equations.

The flame ionization detector has also been used in several gas saturation methods as referred to previously due to its sensitivity to masses in the picogram range.

A kinetic model which included the rates of evaporation, condensation, and dilution of the sample vapor was shown to represent a good approximation to the actual experimental situation, provided the effect of diffusion of the sample vapor was not a large factor. Background measurements, being consistent and negligible, seem to rule out adsorption effects.

Finally, the use of the oxidation oven allows for the determination of the vapor pressure of compounds in lower ranges than otherwise possible due to the combusting of all carbon atoms. Thereby, a substance with a vapor pressure of, for example, $10^{-8}$ torr containing 100 carbon atoms will register a carbon vapor pressure of $10^{-6}$ torr. This value is in the range of the vapor pressures studied.

Other attributes of this method include the fact that only one calibration, that for the $\mathrm{CO}_{2}$ peak was needed in order that the vapor pressures of all organic compounds might be determined. Also, the variable flow procedure needs only a very small size sample for determinations, although approximately 0.1-0.2 g. of sample was used in this study for all samples. 


\section{CHAPTER $V$}

\section{CONCLUSIONS}

This study, using a kinetic model for a variable flow method of measuring the vapor pressures of benzoic acid, naphthalene, benzophenone, and phenylhydrazine, followed the literature values, where applicable, within the estimated experimental error. Temperature fluctuations within experimental trials led to estimated error of as much as $17 \%$. The calculated heats of sublimation from the data for benzoic acid $(25.5 \mathrm{kcal} / \mathrm{mol})$ and naphthalene $(14.3 \mathrm{kcal} / \mathrm{mol})$ were also 15-20\% different than the literature values. For both of these substances, the lower temperature data agreed more closely with the literature values. This coincided with the larger variation in temperature at higher temperatures. The data agreed more closely with the higher vapor pressure substances (i.e., naphthalene and phenylhydrazine). This is attributed to the smaller pressure variation with temperature changes at ambient temperatures for these substances.

The method used here appears to be worthy of further testing under more controlled conditions. Advantages for environmental and other uses are numerous, as explained previously. 


\section{REFERENCES}

1. Zwolinski, B. J. and Wilholt, R. C. Handbook of Vapor Pressures and Heats of Vaporization of Hydrocarbons and Related Compounds, API-44, TRC Publication No. 101, Texas A\&M University (1971).

2. Eggertsen, F. T., Nygard, N. R., and Nicoley, L. D. Ana T. Chem., $1960,52,2069-2072$.

3. Be11, G. H. and Groszek, A. J. J. Inst. Petrol., 1962, 48, 325-332.

4. Power, W. H., Woodward, C. L., and Loughary, W. G. J. Chrom. Sci., $1977,15,203-207$.

5. Macknick, A. B. and Prausnitz, J. M. J. Chem. Eng. Data, 1979, 24 (3), 175-178.

6. Raw7s, R. L. Chem. \& Eng. News, 1979, 57(7), 23-29.

7. Ember, L. R. Chem. \& Eng. News, 1980, 56(32), 22-29.

8. Mackay, D. and Shiu, W. Y. J. Phys. Chem. Ref. Data, 1981, 10(4), 1175-1199.

9. Spencer, W. F. and Cliath, M. M. Soil Sci. Soc. Amer. Proc., 1970, $34,574-578$.

10. Spencer, W. F., Shoup, T. D., Cliath, M. M., Farmer, W. J., and Hague, Riswanut J. Agric. Food Chem., 1979, $27(2), 273-278$.

11. Hamaker, J. W. and Kerlinger, H. C. Advances Chem. Ser., 1969, 86,39 .

12. Kozlowski, E. and Namiesnik, J. Mikrochimica Acta, 1979, 1, 1-15.

13. Johnson, R. L. and Huntzicker, J. J. from Carbonaceous Particles in The Atmosphere Proc., March 20-22, 1978, Lawrence Berkeley Laboratory, University of California, 10-13.

14. Purne11, J. H. Endeavour, 1964, 23(90), 142-147.

15. Duty, R. C. J. Chrom. Sci., 1966, 4, 115-120.

16. Gil'denblat, I. A., Furmanov, A. S., and Zharonkov, N. M. Zhurnal Prikl. Khim., 1960, 33, 246. 
17. Sinke, G. C. J. Chem. Thermo., 1974, 6, 311-316.

18. Bradley, R. S. and Cleasby, T. C. J. Chem. Soc., 1953, 1690.

19. van Ginkel, C. H. D., de Kruif, C. G., and de Waal, F. E. B. J. Phys. E: Sci. Instr., 1975, 8, 490-492.

20. Winstrom, L. 0. and Kulp, L. Ind. and Eng. Chem., 1949, 41(11), 2584-2586.

21. Lange's Handbook of Chemistry, N. A. Lange, ed., 1973, Ohio.

22. Sears, G. W. and Hopke, E. R. J. Am. Soc., 1949, 71, 1632-1633.

23. Ambrose, D., Lawrenson, I. J., and Sprake, C. H. S. J. Chem. Thermo., 1975, 7, 1173-1176.

24. Driesbach, R. R. Adv. Chem. Ser., 1955, 15, 203.

25. ASTM Annual Book of ASTM Standards, Part 23, R. P. Lukens et al, eds., Am. Soc. for Testing and Materials, Easton, Md., 1982, D2551-80.

26. ASTM Annual Book of ASTM Standards, Part 24, R. P. Lukens et al, eds., Am. Soc. for Testing and Materials, Easton, Md., 1982, D323-82.

27. ASTM Annual Book of ASTM Standards, Part 25, R. P. Lukens et a 1 , eds., Am. Soc. for Testing and Materials, Easton, Md., 1982, D2878-85.

28. Sears, G. W. and Hopke, E. R. J. Phys. Chem., 1948, 52, 1137.

29. Hopke, E. R. and Sears, G. W. J. Am. Chem. Soc., 2948, 70, 3801-3803.

30. Thomson, G. W. in Physical Methods of Organic Chemistry, 2nd ed., A. Weissburger, ed., Interscience, N.Y., 1949, Chapter 9.

31. de Kruif, C. G. J. Chem. Thermo., 1983, 15, 129.

32. Knudsen, M. Ann. Physik., 1909, 28, 999.

33. Swan, T. H. and Mack, E., Jr. J. Am. Chem. Soc., 1925, 47, 2112.

34. de Kruif, C. G. and van Ginkel, C. D. H. J. Phys. E: Sci. Instr., $1973,6,764-766$.

35. Friedrich, K. and Stammbach, K. J. Chrom., 1964, 6, 22-28. 
36. Porter, P. E., Deal, C. H., and Stross, F. H. J. Am. Chem. Soc., $1956,78,2999-3006$.

37. Principles and Practices of Gas Chromatography, Robert L. Pecsok, ed., Wiley, N.Y., 1959, 86.

38. Perkin-Elmer Model 3920 Gas Chromatograph manual, Perkin-Elmer Instrument Division, Norwalk, Conn., 1974, Flame Ionization Detector, 6-4 and 6-5.

39. Allen, R. W. J. Chem Soc. $1900,77,410$.

40. Andrews, M. R. J. Phys. Chem., 1926, 30, 1497.

41. Barker, J. T. Z. Physik. Chem., 1910, 71, 235.

42. Thomas, J. S. G. J. Soc. Chem. Ind., 1916, 35, 506-513. 